\title{
Comparative Numerical Study of Thermal Features Analysis between Oldroyd-B Copper and Molybdenum Disulfide Nanoparticles in Engine-Oil-Based Nanofluids Flow
}

\author{
Faisal Shahzad ${ }^{1}$, Wasim Jamshed ${ }^{1}$, Rabha W. Ibrahim ${ }^{2} \mathbb{D}$, Kottakkaran Sooppy Nisar ${ }^{3}$, \\ Muhammad Amer Qureshi ${ }^{4,5}$ (D), Syed M. Hussain ${ }^{6}\left(D_{)}\right.$, Siti Suzilliana Putri Mohamed Isa ${ }^{7,8}$ (D), \\ Mohamed R. Eid ${ }^{9,10, *(\mathbb{D}}$, Abdel-Haleem Abdel-Aty ${ }^{11,12} \mathbb{D}$ and I. S. Yahia ${ }^{13,14,15} \mathbb{D}$
}

check for updates

Citation: Shahzad, F.; Jamshed, W.; Ibrahim, R.W.; Sooppy Nisar, K.; Qureshi, M.A.; Hussain, S.M.; Mohamed Isa, S.S.P.; Eid, M.R.; Abdel-Aty, A.-H.; Yahia, I.S. Comparative Numerical Study of Thermal Features Analysis between Oldroyd-B Copper and Molybdenum Disulfide Nanoparticles in EngineOil-Based Nanofluids Flow. Coatings 2021, 11, 1196. https://doi.org/ $10.3390 /$ coatings 11101196

Academic Editors: Rahmat Ellahi and Mikhail Sheremet

Received: 10 August 2021

Accepted: 24 September 2021

Published: 30 September 2021

Publisher's Note: MDPI stays neutral with regard to jurisdictional claims in published maps and institutional affiliations.

Copyright: (C) 2021 by the authors. Licensee MDPI, Basel, Switzerland This article is an open access article distributed under the terms and conditions of the Creative Commons Attribution (CC BY) license (https:// creativecommons.org/licenses/by/ $4.0 /)$
1 Department of Mathematics, Capital University of Science and Technology (CUST), Islamabad 44000, Pakistan; dmt143019@cust.pk (F.S.); dmt143004@cust.pk (W.J.)

2 Institute of Electrical and Electronics Engineers (IEEE: 94086547), Kuala Lumpur 59200, Malaysia; rabhaibrahim@yahoo.com

3 Department of Mathematics, Prince Sattam Bin Abdulaziz University, Wadi Aldawaser 11991, Saudi Arabia; n.sooppy@psau.edu.sa

4 Preparatory Year Program(PYP)-Mathematics, College of General Studies, King Fahd University of Petroleum and Minerals, Dhahran 31261, Saudi Arabia; qureshi@kfupm.edu.sa

5 Interdisciplinary Research Center for Hydrogen and Energy Storage, King Fahd University of Petroleum and Minerals, Dhahran 31261, Saudi Arabia

6 Department of Mathematics, Faculty of Science, Islamic University of Madinah, Madinah 42351, Saudi Arabia; hussain.modassir@yahoo.com

7 Institute for Mathematical Research, Universiti Putra Malaysia, Serdang 43400, Malaysia; ctsuzilliana@upm.edu.my

8 Centre of Foundation Studies for Agricultural Science, Universiti Putra Malaysia, Serdang 43400, Malaysia

9 Department of Mathematics, Faculty of Science, New Valley University, Al-Kharga 72511, Egypt

10 Department of Mathematics, Faculty of Science, Northern Border University, Arar 1321, Saudi Arabia

11 Department of Physics, College of Sciences, University of Bisha, P.O. Box 344, Bisha 61922, Saudi Arabia; amabdelaty@ub.edu.sa

12 Physics Department, Faculty of Science, Al-Azhar University, Assiut 71524, Egypt

13 Advanced Functional Materials \& Optoelectronic Laboratory (AFMOL), Department of Physics, Faculty of Science, King Khalid University, P.O. Box 9004, Abha 61413, Saudi Arabia; isyahia@gmail.com

14 Research Center for Advanced Materials Science (RCAMS), King Khalid University, P.O. Box 9004, Abha 61413, Saudi Arabia

15 Nanoscience Laboratory for Environmental and Biomedical Applications (NLEBA), Semiconductor Lab., Department of Physics, Faculty of Education, Ain Shams University, Roxy, Cairo 11757, Egypt

* Correspondence: m_r_eid@yahoo.com

Abstract: Apart from the Buongiorno model, no effort was ably accomplished in the literature to investigate the effect of nanomaterials on the Oldroyd-B fluid model caused by an extendable sheet. This article introduces an innovative idea regarding the enforcement of the Tiwari and Das fluid model on the Oldroyd-B fluid (OBF) model by considering engine oil as a conventional base fluid. Tiwari and Das's model takes into account the volume fraction of nanoparticles for heat transport enhancement compared to the Buongiorno model that depends significantly on thermophoresis and Brownian diffusion impacts for heat transport analysis. In this paper, the thermal characteristics of an Oldroyd-B nanofluid are reported. Firstly, the transformation technique is applied on partial differential equations from boundary-layer formulas to produce nonlinear ordinary differential equations. Subsequently, the Keller-box numerical system is utilized to obtain final numerical solutions. Copper engine oil $(\mathrm{Cu}-\mathrm{EO})$ and molybdenum disulfide engine oil $\left(\mathrm{MoS}_{2}-\mathrm{EO}\right)$ nanofluids are considered. From the whole numerical findings and under the same condition, the thermodynamic performance of $\mathrm{MoS}_{2}-\mathrm{EO}$ nanofluid is higher than that of $\mathrm{Cu}-\mathrm{EO}$ nanofluid. The thermal efficiency of $\mathrm{Cu}-\mathrm{EO}$ over $\mathrm{MoS}_{2}-\mathrm{EO}$ is observed between $1.9 \%$ and $43 \%$. In addition, the role of the porous media parameter is to reduce the heat transport rate and to enhance the velocity variation. Finally, the impact of the numbers of Reynolds and Brinkman is to increase the entropy. 
Keywords: Oldroyd-B nanofluid; entropy generation; variable thermal conductivity; Keller-box method

\section{Introduction}

In 1995, Choi [1] first presented the idea of nanofluid. Their main observation was that the thermal conductivity increased when a low rate of copper nanoparticles was immersed in water. Consequently, numerous mixtures of nanoparticles and liquids have been investigated for improving transport phenomena and thermophysical properties, such as thermal conductivity. Characteristic materials utilized for synthesizing nanofluids include metals, inorganic oxides, carbon-based resources, and other porcelains. Meanwhile, a popular selection of cleaners contains aquatic, ionic liquids, glycols, biological liquids, and refrigerants. Other fluids discovered in research works contain oils, biofluids, mixtures, fuels, alcohols, melted salt eutectics, etc. The preferred fluid properties are important for the selected process, to facilitate the optimal combination procedure for a specific nanofluid. Consequently, it is critical to develop a collection of mixture procedures for the nanofluids' choice group, when subjected to objective properties and processes [2-6].

Another significant issue in nanofluids preparation is long-term stability. Therefore, the nanomanufacturing field was established, producing nanoparticles with various scopes, forms, and construction. Nonetheless, protecting nanoparticle suspension homogeneously in the base fluid for a sufficient long time is a challenging task. Therefore, many methods have been developed to grow the suspensions' stability, and they have fundamentally produced short-range stability. However, no specific investigations have been conducted to confirm long-range stability. The strategic reason for keeping nanoparticle suspensions stable for extended periods of time is to avoid nanoparticle agglomeration. For instance, high thermal conductivity is desirable in heat transmission processes. At the same time, non-Newtonian rheological performance and load-carrying capacity are carefully selected in lubrication processes to vanish heat rapidly.

One significant consideration in a nanofluid composition is the cost and practicability of scaling up to a combination of outsized capacities. Unfortunately, such engineering considerations are usually ignored in critical investigations. Still, they are fundamental to the commercial achievement of nanofluids, if this technology were to enter conservative and novel manufacturing processes [7-10].

Accordingly, it is imperative to recognize, model, and maximize the combination environments to allow superior control over the transport instruments, such as similar or dissimilar nucleation of the nanoparticles compared to the originators or the development and monitoring of the accumulation of the nanoparticles generated. Recently, an increased number of studies on non-Newtonian fluids has been introduced by numerous researchers, because of their excellent reputation in many industrial and chemical activities, nuclear production, bioengineering, geophysics, and material processing. Therefore, the importance of non-Newtonian fluids is still puzzling, and thus, many non-Newtonian designs are being investigated to demonstrate their composite rheological perspective. Among these non-Newtonian fluids, the Oldroyd-B fluid (OBF) releases with synchronized relaxation and retardation times. Furthermore, OBF allows clarifying the creep and standard stress changes, which are related to simple shear flow. Nevertheless, the OBF does not define the shear condensing and shear withdrawing structures, unlike other polymeric materials. The OBF contains viscoelastic applications for Maxwell and viscous fluids for example. Based on such remarkable properties, the flow of OBF was thoroughly investigated in the literature [11-18]. Moreover, researchers have explained the effect of slip boundary conditions in nanofluids past the extending slip $[19,20]$.

Entropy computes the amount of chaos in a system and its environment, which describes the impact of heat transfer on the alterations in kinetic energy and potential energy. The analysis of entropy generation can describe the heat losing progression of a fluid wave. Researchers have utilized the entropy generation analysis in fluid flow, aiming at two rotat- 
ing disks moving with different rotation rates. It indicated that because of every thermal progression, the entropy measures the quantity of irreversibility. Therefore, conserving and warming are the most critical issues in numerous industrial fields of engineering investigations, which are utilized primarily on energy and electronic devices [21-28].

Based on the abovementioned literature, none of the published research works independently considered a Tiwari-Das nanofluid scheme [29] over the stretching sheet, together with the impacts of controlling parameters such as penetrable materials, variant thermal conductance, radiation heat flux, and slip conditions. Hence, the current study emphasizes the mentioned controlling parameters and entropy on an OBF using a specific numerical method, namely, the Keller-box method.

\section{Mathematical Formulation}

This analysis considers a steady, laminar two-dimensional heat transfer flow of the incompressible Oldroyd-B nanofluid through an extending sheet with first-order slip, convective endpoint conditions, and passive control of different nanoparticles. Equation (1) characterizes the moving flat horizontal surface with the nonuniform expanding velocity $U_{w}$, where $b$ is a positive constant. (Figure 1 ).

$$
U_{w}(x, 0)=b x
$$

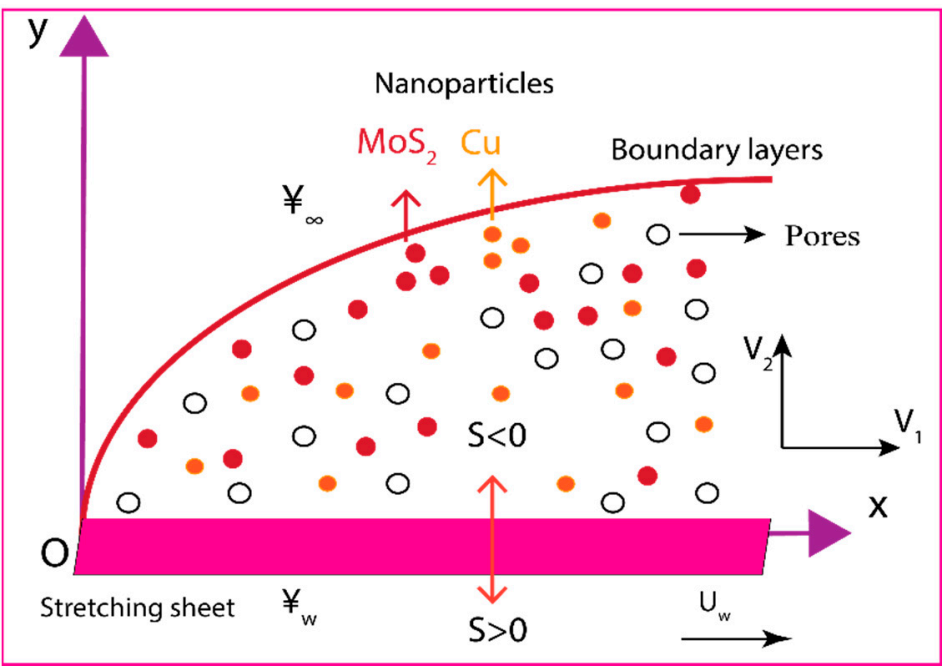

Figure 1. Schematic diagram of the flow model.

\subsection{Model Equations}

The basic time-independent governing equations of mass, momentum, and thermal energy of a viscous Oldroyd-B nanofluid flow employing customary boundary-layer approximations, subjected to a porous media, and variable thermal conductivity with radiation heat flux are [30]:

$$
\frac{\partial v_{1}}{\partial x}+\frac{\partial v_{2}}{\partial y}=0
$$

$$
\begin{aligned}
& v_{1} \frac{\partial v_{1}}{\partial x}+v_{2} \frac{\partial v_{1}}{\partial y}+ \lambda_{1}\left[v_{1}^{2} \frac{\partial^{2} v_{1}}{\partial x^{2}}+v_{2}^{2} \frac{\partial^{2} v_{1}}{\partial y^{2}}+2 u v \frac{\partial^{2} v_{1}}{\partial x \partial y}\right] \\
&= \frac{\mu_{n f}}{\rho_{n f}}\left[\left(\frac{\partial^{2} v_{1}}{\partial y^{2}}\right)-\frac{v_{1}}{k}\right]+\frac{\mu_{n f}}{\rho_{n f}}\left[\lambda_{2}\left(v_{1}\left(\frac{\partial^{3} v_{1}}{\partial x \partial y^{2}}\right)-\frac{\partial v_{1}}{\partial x}\left(\frac{\partial^{2} v_{1}}{\partial y^{2}}\right)+\frac{\partial v_{1}}{\partial y}\left(\frac{\partial^{2} v_{2}}{\partial y^{2}}\right)+v_{2}\left(\frac{\partial^{3} v_{1}}{\partial y^{3}}\right)\right)\right], \\
& v_{1} \frac{\partial ¥}{\partial x}+v_{2} \frac{\partial ¥}{\partial y}=\frac{1}{\left(\rho C_{p}\right)_{n f}}\left[\frac{\partial}{\partial y}\left(\kappa_{n f}^{*}(¥) \frac{\partial ¥}{\partial y}\right)\right]-\frac{1}{\left(\rho C_{p}\right)_{n f}} \frac{\partial q_{r}}{\partial y} .
\end{aligned}
$$


The relevant boundary conditions are [31]:

$$
\left.\begin{array}{c}
v_{1}(x, 0)=U_{w}+N v\left(\frac{\partial v_{1}}{\partial y}\right), v_{2}(x, 0)=V_{w},-k_{0}\left(\frac{\partial ¥}{\partial y}\right)=h_{f}\left(¥ \Psi_{w}-¥\right), \text { at } y=0 \\
v_{1} \rightarrow 0, \frac{\partial v_{1}}{\partial y} \rightarrow 0, ¥ \rightarrow ¥_{\infty} \text { as } y \rightarrow \infty .
\end{array}\right\}
$$

where $V_{w}$ signifies suction (injection) parameter.

\subsection{Thermophysical Features of the Oldroyd-B Nanofluid}

Thermophysical characteristics are increased by the dispersion of nanoparticles into an aqueous fluid. The material parameters for the Oldroyd-B nanofluid are offered in Table $1[32,33]$ :

Table 1. Thermophysical features of the Oldroyd-B nanofluid.

\begin{tabular}{cl}
\hline Features & \multicolumn{1}{c}{ Nanofluid } \\
\hline Viscosity $(\mu)$ & $\mu_{n f}=\mu_{f}(1-\phi)^{-2.5}$ \\
Density $(\rho)$ & $\rho_{n f}=(1-\phi) \rho_{f}+\phi \rho_{s}$ \\
Heat capacity $\left(\rho C_{p}\right)$ & $\left(\rho C_{p}\right)_{n f}=(1-\phi)\left(\rho C_{p}\right)_{f}+\phi\left(\rho C_{p}\right)_{s}$ \\
Thermal conductivity $(\kappa)$ & $\frac{\kappa_{n f}}{\kappa_{f}}=\left[\frac{\left(\kappa_{s}+2 \kappa_{f}\right)-2 \phi\left(\kappa_{f}-\kappa_{s}\right)}{\left(\kappa_{s}+2 \kappa_{f}\right)+\phi\left(\kappa_{f}-\kappa_{s}\right)}\right]$ \\
\hline
\end{tabular}

In Table $1, \mu_{f}, \rho_{f},\left(C_{p}\right)_{f}$, and $\kappa_{f}$ are defined as the nanoparticle volumetric fraction coefficient, dynamic viscosity, intensity, effective heat capacitance, and thermal conductance of the base fluid, respectively. The other properties $\rho_{s},\left(C_{p}\right)_{s}$, and $\kappa_{s}$ are denoted as the density, effective heat capacitance, and thermal conductance of the nanoparticles, respectively. The variable thermal conductance is defined as [33,34]:

$$
\kappa_{n f}^{*}(¥)=k_{n f}\left[1+\epsilon \frac{¥-¥_{\infty}}{¥_{w}-¥_{\infty}}\right]
$$

\subsection{Nanosolid-Particles and Base Fluid Attributes}

The physical characteristics of the base fluid engine oil and various nanosolid particles are tabulated in Table 2 below [35,36].

Table 2. Material characteristics of base fluid and nanosolid particles at $293 \mathrm{~K}$.

\begin{tabular}{cccc}
\hline Thermophysical & $\rho\left(\mathrm{kg} / \mathbf{m}^{3}\right)$ & $c_{p}(\mathrm{~J} / \mathbf{k g} \cdot \mathbf{K})$ & $k(\mathrm{~W} / \mathbf{m K})$ \\
\hline Copper $(\mathrm{Cu})$ & 8933 & 385.0 & 401.00 \\
Engine Oil (EO) & 884 & 1910 & 0.144 \\
Molybdenum disulfide $\left(\mathrm{MoS}_{2}\right)$ & 5060 & 397.21 & 904.4 \\
\hline
\end{tabular}

\subsection{Rosseland Approximations}

Using the Roseland approximation [37], one can write:

$$
q_{r}=-\frac{4 \sigma^{*}}{3 k^{*}} \frac{\partial ¥^{4}}{\partial y}
$$

Here, $\sigma^{*}$ is the Stefan-Boltzmann number and $k^{*}$ is the absorption coefficient.

\section{The Solution to the Problem}

The boundary value problem in Equations (2)-(5) is in the form of PDEs, which are converted into ODEs with the assistance of the similarity technique. The first step of this 
technique is to introduce stream functions $\psi$ and subsequently, $\psi$ is used to express the velocity components in the $x$ and $y$ axes.

$$
v_{1}=\frac{\partial \psi}{\partial y}, v_{2}=-\frac{\partial \psi}{\partial x}
$$

Then, similarity variables are formed as:

$$
Y(x, y)=\sqrt{\frac{b}{v_{f}}} y, \psi(x, y)=\sqrt{v_{f} b} x f(Y), \theta(Y)=\frac{¥-¥_{\infty}}{¥_{w}-¥_{\infty}} .
$$

When Equation (9) is substituted into Equations (2)-(5), then the following ODEs are obtained:

$$
\begin{gathered}
f^{\prime \prime \prime}+\phi_{\mathrm{a}} \phi_{\mathrm{b}}\left[f f^{\prime \prime}-f^{\prime 2}+\beta_{1}\left(2 f f^{\prime}-f^{2} f^{\prime \prime \prime}\right)\right]+\beta_{2}\left(f^{\prime \prime 2}-f f^{i v}\right)-\frac{1}{\phi_{\mathrm{a}}} K f^{\prime}=0, \\
\theta^{\prime \prime}\left(1+\epsilon \theta+\frac{1}{\phi_{\mathrm{d}}} \operatorname{Pr} N r\right)+\epsilon \theta^{\prime 2}+\operatorname{Pr} \frac{\phi_{\mathrm{c}}}{\phi_{\mathrm{d}}}\left(f \theta^{\prime}-f^{\prime} \theta\right)=0,
\end{gathered}
$$

with

$$
\left.\begin{array}{l}
f(0)=S, f^{\prime}(0)=1+\Lambda f^{\prime \prime}(0), \theta^{\prime}(0)=-B_{\zeta}(1-\theta(0)) \\
f^{\prime}(\infty) \rightarrow 0, f^{\prime \prime}(\infty) \rightarrow 0, \theta(\infty) \rightarrow 0,
\end{array}\right\}
$$

where the $\phi_{i}^{\prime} s$ with a $\leq i \leq \mathrm{d}$ in Equations (10)-(12) represent the following thermophysical properties for the Oldroyd-B nanofluid

$$
\left.\begin{array}{l}
\phi_{\mathrm{a}}=(1-\phi)^{2.5}, \phi_{\mathrm{b}}=\left(1-\phi+\phi \frac{\rho_{s}}{\rho_{f}}\right), \phi_{\mathrm{c}}=\left(1-\phi+\phi \frac{\left(\rho C_{p}\right)_{s}}{\left(\rho C_{p}\right)_{f}}\right) \\
\phi_{\mathrm{d}}=\left(\frac{\left(k_{s}+2 k_{f}\right)-2 \phi\left(k_{f}-k_{s}\right)}{\left(k_{s}+2 k_{f}\right)+\phi\left(k_{f}-k_{s}\right)}\right) .
\end{array}\right\}
$$

As Equation (2) satisfies identity, the notation $\left(^{\prime}\right)$ is used for representing the derivatives for $Y$. Here, $\beta_{1}=b \lambda_{1}$ (Deborah number-I), $\beta_{2}=b \lambda_{2}$ (Deborah number-II) defined along with $K=\frac{v_{f}}{b k}$ (porous medium) parameter and $\operatorname{Pr}=\frac{v_{f}}{\alpha_{f}}$ (Prandtl number), $\alpha_{f}=\frac{\kappa_{f}}{\left(\rho C_{p}\right)_{f}}$ (thermal diffusivity), $S=-V_{w} \sqrt{\frac{1}{v_{f} b}}$ (mass transfer), $N r=\frac{16}{3} \frac{\sigma^{*} Y==_{\infty}^{3}}{\kappa^{*} v_{f}\left(\rho C_{p}\right)_{f}}$ (thermal radiation), $\Lambda=\sqrt{\frac{b}{v_{f}}} N v$ (velocity slip), and $B_{\varsigma}=\frac{h_{f}}{k_{0}} \sqrt{\frac{v_{f}}{b}}$ (Biot number) parameters, respectively.

\subsection{Nusselt Number}

The local Nusselt number $\left(N u_{x}\right)$ is the physical parameter that controls the flow and can be expressed as [38,39]:

$$
N u_{x}=\frac{x q_{w}}{k_{f}\left(¥_{w}-¥_{\infty}\right)}
$$

wherein $q_{w}$ indicates the heat flux, which is presented in Equation (15):

$$
q_{w}=-k_{n f}\left(1+\frac{16}{3} \frac{\sigma^{*} ¥_{\infty}^{3}}{\kappa^{*} v_{f}\left(\rho C_{p}\right)_{f}}\right)\left(\frac{\partial ¥}{\partial y}\right)_{y=0}
$$

Applying the nondimensional transformations (9), one obtains:

$$
N u_{x} R e_{x}^{-\frac{1}{2}}=-\frac{k_{n f}}{k_{f}}(1+N r) \theta^{\prime}(0),
$$

where $N u_{x}$ and $C_{f}$ denote the Nusselt number and reduced skin friction, respectively. In addition, $R e_{x}=\frac{U_{w} x}{v_{f}}$ is the local $R e$ which relies on the stretching velocity $U_{w}(x)$. 


\subsection{Entropy Generation Analysis}

Researchers in science and technology are always considering the amount of energy used and trying to minimize the wasted energy. Therefore, the reduction of entropy generation is a good decision, since entropy generation is one of the main factors that cause the irreversibility of convenient energy. A nonideal factor that contributes to an increment in the entropy of the system is the presence of penetrable materials. When penetrable materials affect the density of a nanofluid, the following effects arise: First, the medium's permeability decreases, and then the thermal boundary layer and the system entropy increase. Therefore, the real entropy production in the nanofluids can be expressed by [38-41]:

$$
E_{G}=\frac{k_{n f}}{¥_{\infty}^{2}}\left\{\left(\frac{\partial ¥}{\partial y}\right)^{2}+\frac{16}{3} \frac{\sigma^{*} ¥_{\infty}^{3}}{\kappa^{*} v_{f}\left(\rho C_{p}\right)_{f}}\left(\frac{\partial ¥}{\partial y}\right)^{2}\right\}+\frac{\mu_{n f}}{¥_{\infty}}\left(\frac{\partial v_{1}}{\partial y}\right)^{2}+\frac{\mu_{n f} v_{1}^{2}}{k ¥_{\infty}} .
$$

Equation (17) is formed by three terms: the transfer of heat irreversibility, the fluid friction, and the porous media effect. The dimensionless entropy generation $N_{G}$ [42-46] is expressed as:

$$
N_{G}=\frac{¥_{\infty}^{2} b^{2} E_{G}}{k_{f}\left(¥_{w}-T_{\infty}\right)^{2}} .
$$

By substituting Equation (9) into Equation (18), the final equation of dimensionless entropy generation is:

$$
N_{G}=\operatorname{Re}\left[\phi_{4}(1+N r) \theta \prime^{2}+\frac{1}{\phi_{1}} \frac{B r}{\Omega}\left(f^{\prime \prime 2}+K f^{\prime 2}\right)\right] .
$$

\section{Numerical Implementation}

To tackle the nonlinear ordinary differential Equations (10) and (11) concerning the endpoint condition (12), we applied the Keller-box method [47] with the help of algebraic software MATLAB for various values of the involved parameters. The stepwise procedure of the Keller-box method is expressed in the flow chart from Figure 2.

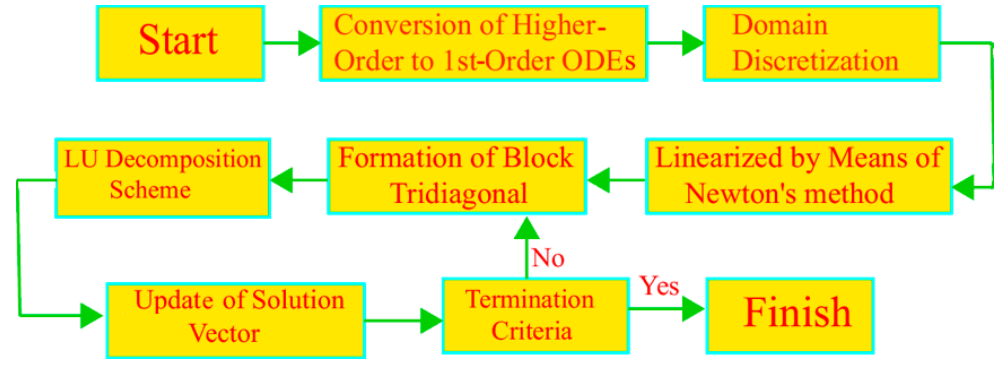

Figure 2. Flow chart illustrating Keller-box method.

\section{Conversion of ODEs}

We have introduced the subsequent substitutions for converting the higher-order ODEs to first-order ODEs. We introduce dependent variables $G v_{1}, G v_{2}, G v_{3}, G v_{4}, G v_{5}$, and Gv 6 such that:

$$
\begin{aligned}
G v_{1}=f, G v_{2}=f^{\prime}, G v_{3} & =f^{\prime \prime}, G v_{4}=f^{\prime \prime \prime}, G v_{5}=\theta, G v_{6}=\theta^{\prime} . \\
\frac{d G v_{1}}{d Y} & =G v_{2}, \\
\frac{d G v_{2}}{d Y} & =G v_{3},
\end{aligned}
$$




$$
\left.\begin{array}{c}
\frac{d G v_{3}}{d \mathrm{Y}}=G v_{4}, \\
\frac{d G v_{5}}{d \mathrm{Y}}=G v_{6}, \\
-\beta_{2} G v_{1} \frac{d G v_{4}}{d \mathrm{Y}}+\beta_{2} G v_{3}^{2}+\phi_{a} \phi_{b} G v_{1} G v_{3}-\phi_{a} \phi_{b} G v_{2}^{2}+2 \phi_{a} \phi_{b} \beta_{1} G v_{1} G v_{2}-\phi_{a} \phi_{b} \beta_{1} G v_{1}^{2} G v_{4}-\frac{1}{\phi_{a}} K G v_{2}+G v_{4}=0, \\
\frac{d G v_{6}}{d \mathrm{Y}}+\epsilon G v_{5} \frac{d G v_{6}}{d \mathrm{Y}}+\frac{1}{\phi_{d}} \operatorname{Pr} N r \frac{d G v_{6}}{d \mathrm{Y}}+\epsilon G v_{6}^{2}+\operatorname{Pr} \frac{\phi_{c}}{\phi_{d}} G v_{1} G v_{6}-\operatorname{Pr} \frac{\phi_{c}}{\phi_{d}} G v_{2} G v_{5}=0, \\
G v_{1}(0)=S, G v_{2}(0)=1+\Lambda G v_{3}(0), G v_{6}(0)=-B_{5}\left(1-G v_{5}(0)\right), \\
G v_{2}(Y) \rightarrow 0, \quad G v_{3}(Y) \rightarrow 0, \quad G v_{5}(Y) \rightarrow 0, \text { as } Y \rightarrow \infty .
\end{array}\right\}
$$

The domain $[0,1]$ has been converted into sub-domains utilizing a regular mesh with the subsequent grid points (Figure 3):

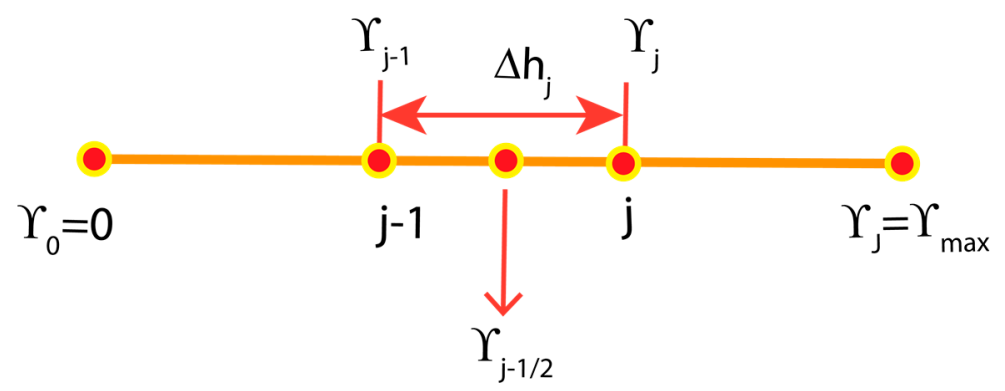

Figure 3. Typical grid structure for difference approximations.

$\mathrm{Y}_{0}=0, \mathrm{Y}_{j}=\mathrm{Y}_{j-1}+\Delta h_{j}, j=0,1,2,3 \ldots, J, \mathrm{Y}_{J}=1$ where, $\Delta h_{j}$ is the step-size (for further details, see Appendix A). For mathematical assessment, a mesh size of $\Delta h_{j}=0.01$ was figured out to be appropriate and the results are acquired with an error tolerance of $10^{-6}$.

\section{Code Validation}

In this section, our numerical results are validated by comparing with the findings from the literature [48-51]. The comparison of consistencies is tabulated in Table 3. It is shown that the present study displayed highly accurate outcomes for $-\theta^{\prime}(0)$ with various values of $P r$ in the limiting cases.

Table 3. Comparison of $-\theta^{\prime}(0)$ with various values of $\operatorname{Pr}$ when $\phi=0, \epsilon=0, \Lambda=0, N r=0, S=0$, and $B_{\zeta}=0$.

\begin{tabular}{cccccc}
\hline $\boldsymbol{P r}$ & Ref. [48] & Ref. [49] & Ref. [50] & Ref. [51] & Present \\
\hline $72 \times 10^{-2}$ & $08086 \times 10^{-4}$ & $08086 \times 10^{-4}$ & $080863135 \times 10^{-8}$ & $080876122 \times 10^{-8}$ & $080876181 \times 10^{-8}$ \\
$1 \times 10^{0}$ & $1 \times 10^{0}$ & $1 \times 10^{0}$ & $1 \times 10^{0}$ & $1 \times 10^{0}$ & $1 \times 10^{0}$ \\
$3 \times 10^{0}$ & $19237 \times 10^{-4}$ & $19236 \times 10^{-4}$ & $192368259 \times 10^{-8}$ & $192357431 \times 10^{-8}$ & $192357420 \times 10^{-8}$ \\
$7 \times 10^{0}$ & $30723 \times 10^{-4}$ & $30722 \times 10^{-4}$ & $307225021 \times 10^{-8}$ & $307314679 \times 10^{-8}$ & $307314651 \times 10^{-8}$ \\
$10 \times 10^{0}$ & $37207 \times 10^{-4}$ & $37006 \times 10^{-4}$ & $372067390 \times 10^{-8}$ & $372055436 \times 10^{-8}$ & $372055429 \times 10^{-8}$ \\
\hline
\end{tabular}

\section{Results and Discussion}

This study aimed to analyze the thermal efficacy of OBF flowing over a stretching surface. The Keller-box numerical approach was applied to calculate numerical and graphical results. The impacts of physical parameters on the two-dimensional model of OBF are reported. These parameters are listed as the boundary layer thickness $Y$, Deborah number $\beta_{1}$ and $\beta_{2}$, porous media parameter $K$, nanoparticle volume fraction parameter $\phi$, velocity slip parameter $\Lambda$, variable thermal conductivity parameter thermal $\epsilon$, radiation parameter $N r$, Biot number $B_{S}$, suction parameter $S>0$, injection parameter $S<0, R_{e}$, 
and $B_{r}$. The characteristics of fluid swiftness, temperature, and entropy production are displayed in Figures 4-31. The results are obtained for the $\mathrm{Cu}-\mathrm{EO}-$ and $\mathrm{MoS}_{2}-\mathrm{EO}-\mathrm{based}$ non-Newtonian Oldroyd-B nanofluid. This numerical investigation was accomplished by setting up the following values for the related factors: $\beta_{1}=0.1, \beta_{2}=0.1, K=0.1$, $\phi=0.1, \Lambda=0.2, \operatorname{Pr}=6450, \epsilon=0.2, \mathrm{Nr}=0.3, B_{\varsigma}=0.1, S=0.1, \operatorname{Re}=5$, and $\mathrm{Br}=5$. The numerical measurements are presented in the form of tables and figures for two components of Oldroyd-B-nanofluid: $\mathrm{Cu}-\mathrm{EO}$ and $\mathrm{MoS}_{2}-\mathrm{EO}$.

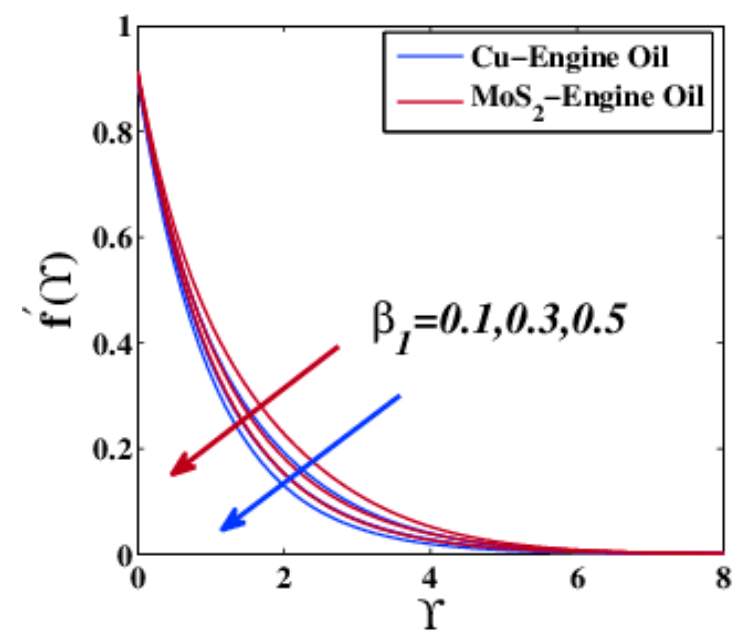

Figure 4. The effect of $\beta_{1}$ on velocity variation $f^{\prime}(Y)$.

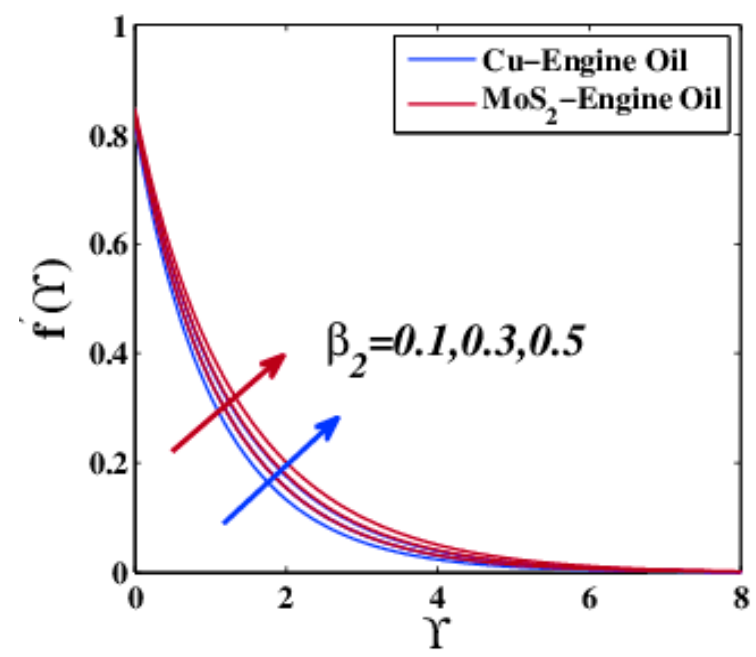

Figure 5. The effect of $\beta_{2}$ on velocity variation $f^{\prime}(Y)$.

Figures 4-9 describe a dimensionless number, known as Deborah number, on the variations of velocity, temperature, and entropy generation. Deborah number is defined as the relaxation time of non-Newtonian fluid, divided by the scale of time flow. The special effects of the Deborah numbers, which are denoted by $\beta_{1}$ and $\beta_{2}$ on velocity component $f^{\prime}(Y)$ are presented in Figures 4 and 5, respectively. It is detected that $f^{\prime}(Y)$ profiles decrease with an increasing value of $\beta_{1}$, and it shows an opposite pattern when it is controlled by parameter $\beta_{2}$. Figures 6 and 7 represent the effect of $\beta_{1}$ and $\beta_{2}$ on temperature profile $\theta(Y)$, respectively. From Figure 6, it is observed that the values of $\theta(Y)$ and their associated thermal boundary layer thicknesses are increased when $\beta_{1}$ rises. A rise in the value of $\beta_{1}$ leads to an increase in reduction time. However, the effect of $\beta_{2}$ causes the temperature profile to drop, as shown in Figure 8. The results of entropy generation $N_{G}$ are presented in Figures 8 and 9 for different values of $\beta_{1}$ and $\beta_{2}$, respectively. From these figures, the impact of the Deborah number $\beta_{1}$ and $\beta_{2}$ is to reduce the entropy generation profile. 


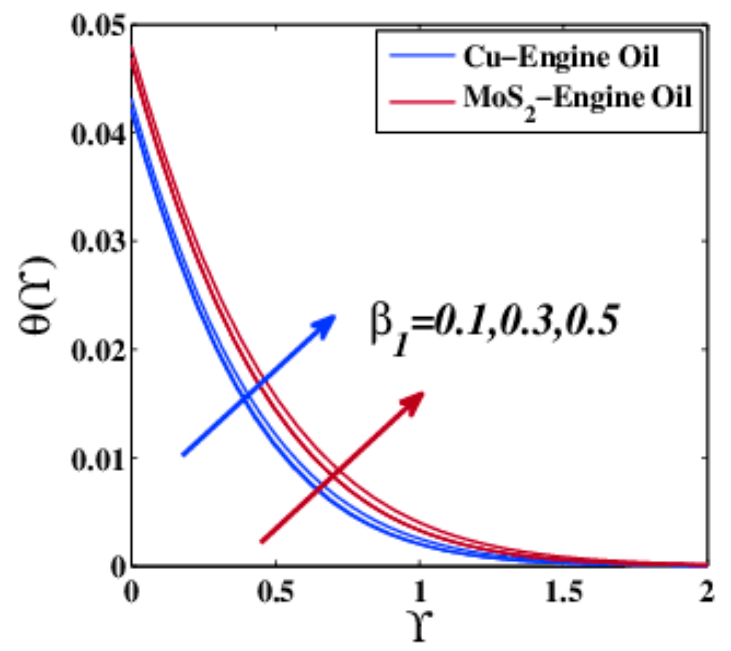

Figure 6. The effect of $\beta_{1}$ on temperature variation $\theta(Y)$.

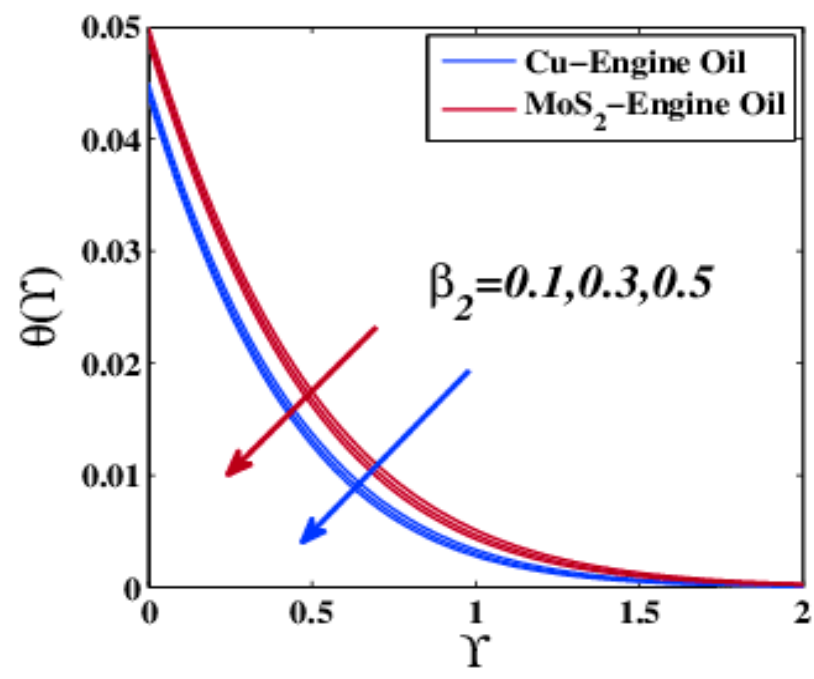

Figure 7. The effect of $\beta_{2}$ on temperature variation $\theta(Y)$.

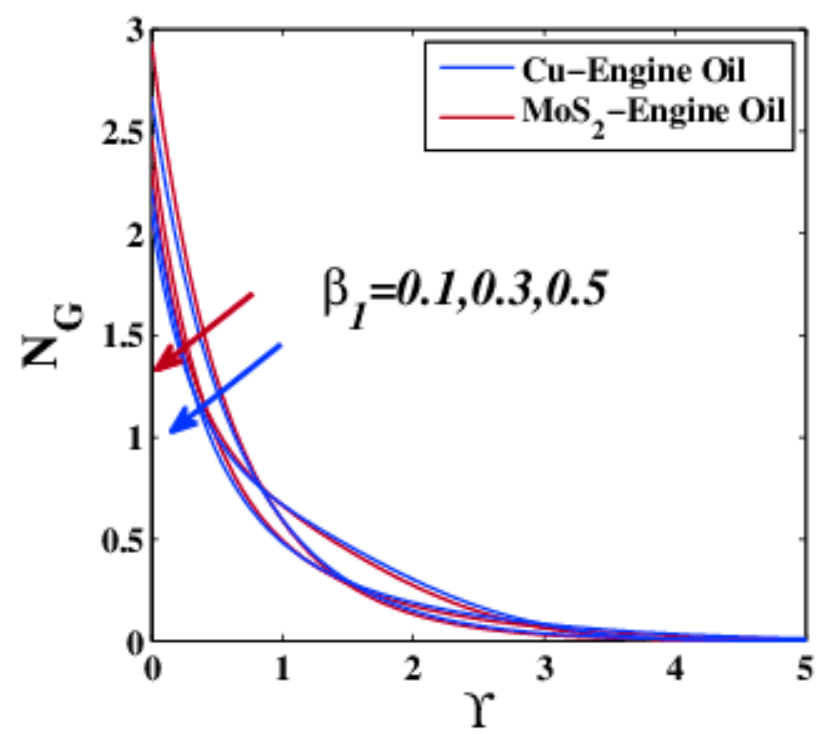

Figure 8. The effect of $\beta_{1}$ on entropy generation variation $N_{G}$. 


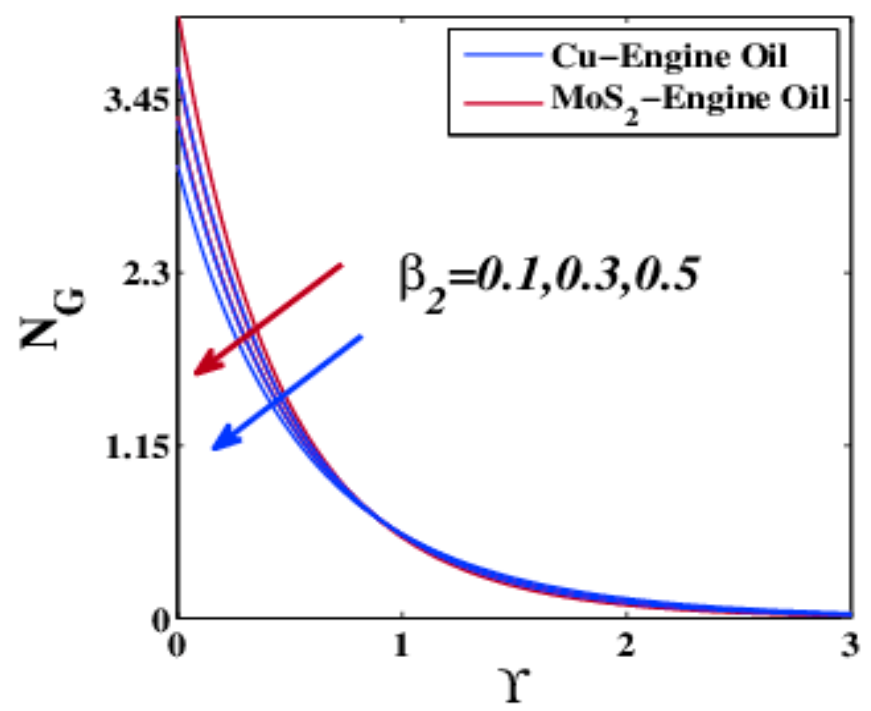

Figure 9. The effect of $\beta_{2}$ on entropy generation variation $N_{G}$.

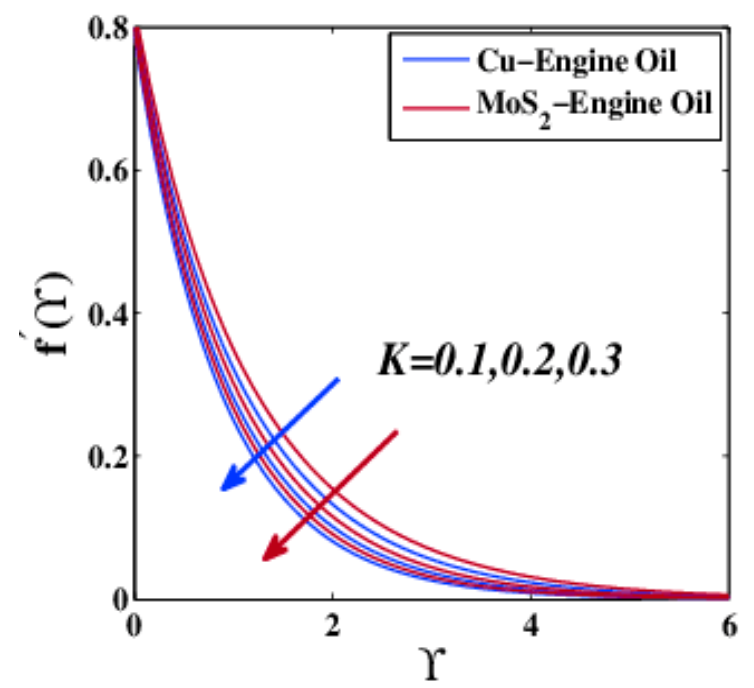

Figure 10. Velocity variation $f^{\prime}(Y)$ under the influence of $K$.

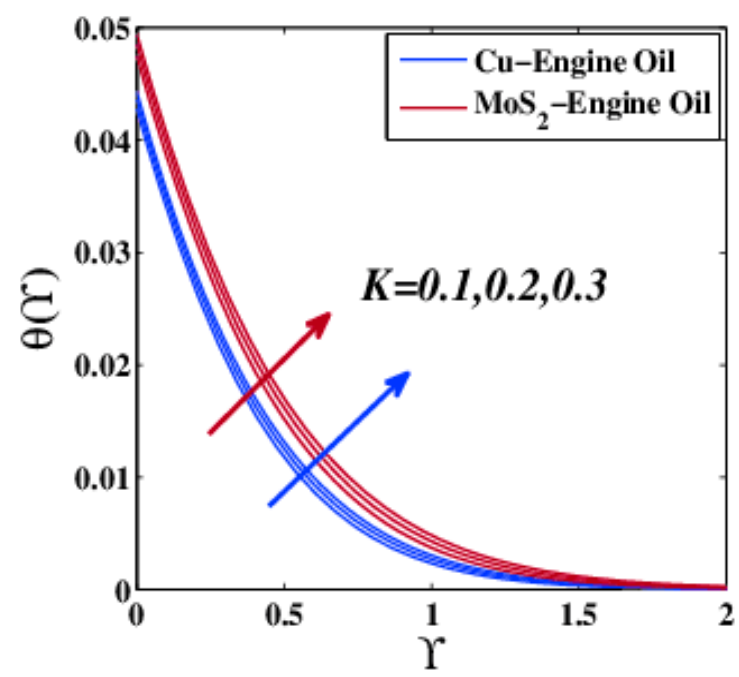

Figure 11. Temperature variation $\theta(Y)$ under the influence of $K$. 


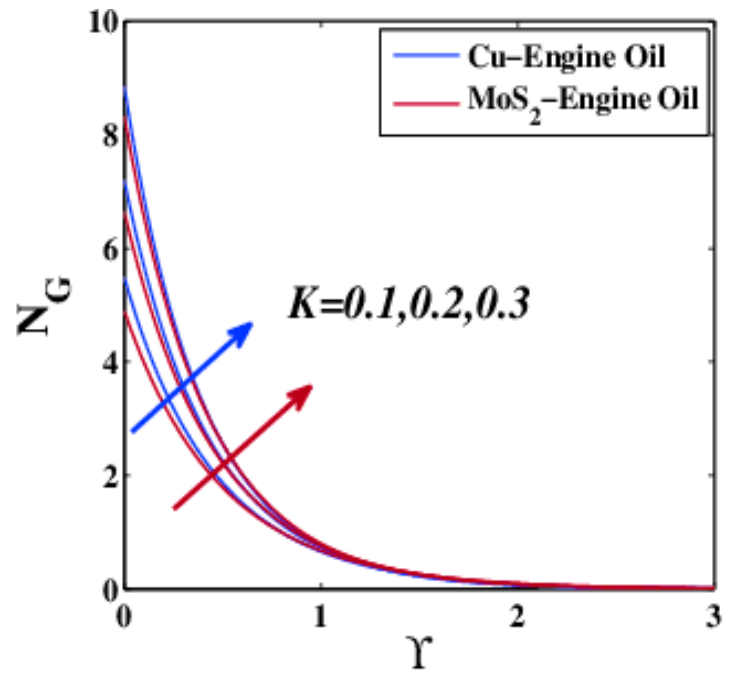

Figure 12. Entropy generation variation $N_{G}$ under the influence of $K$.

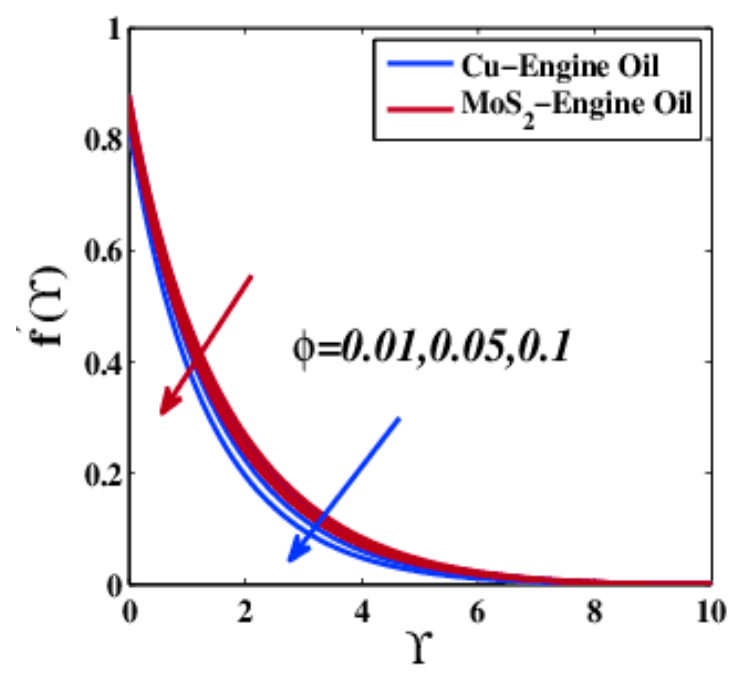

Figure 13. Velocity variation $f^{\prime}(Y)$ under the influence of $\phi$.

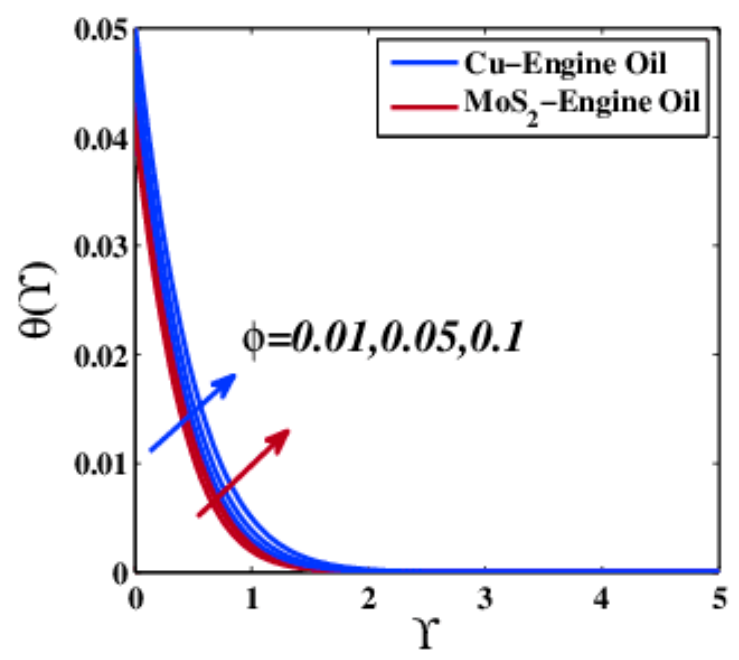

Figure 14. Temperature variation $\theta(Y)$ under the influence of $\phi$. 


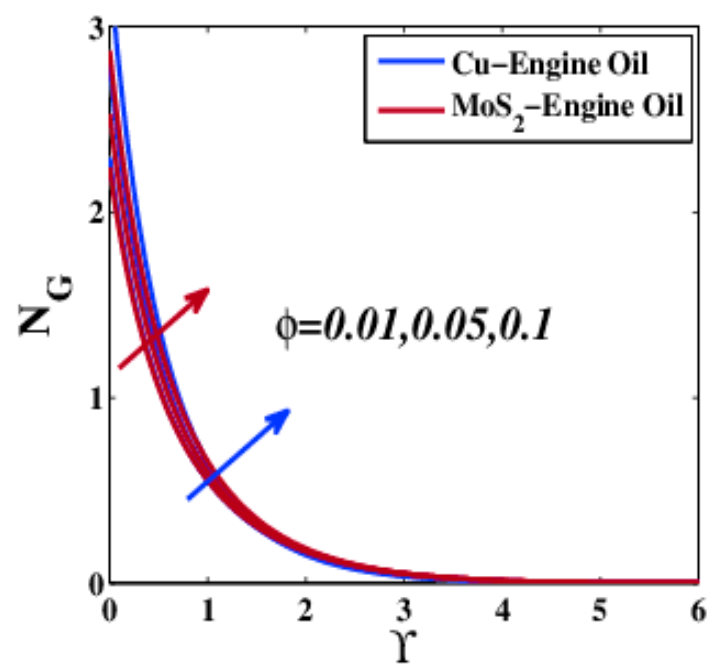

Figure 15. Entropy generation variation $N_{G}$ under the influence of $\phi$.

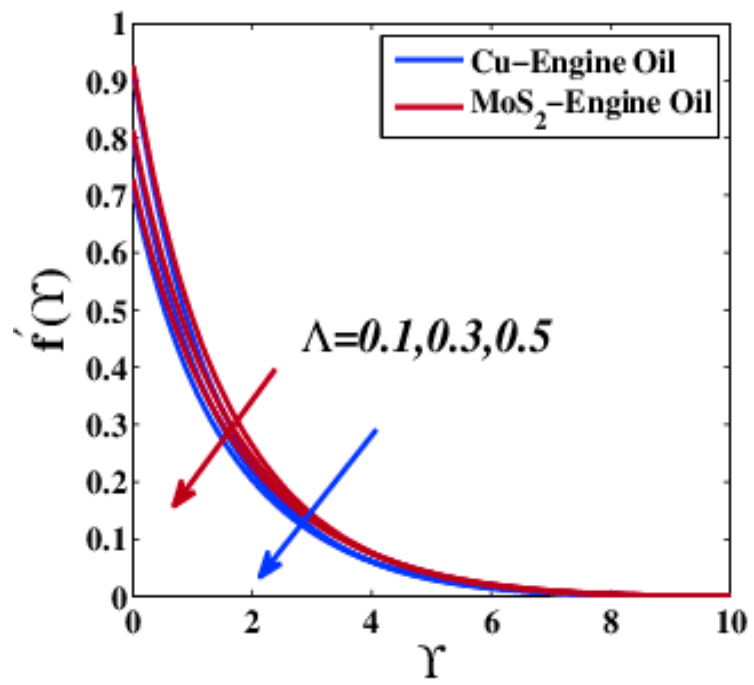

Figure 16. Velocity variation $f^{\prime}(Y)$ under the influence of $\Lambda$.

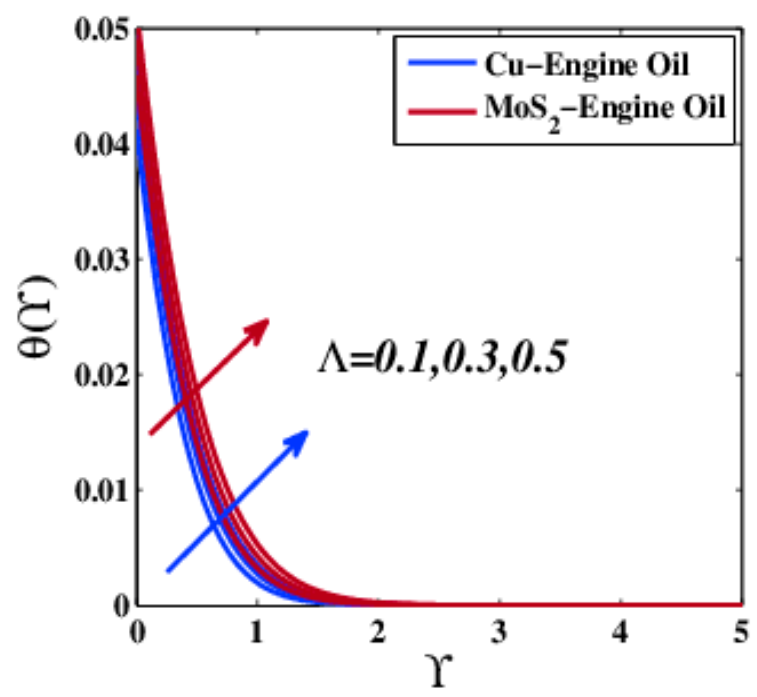

Figure 17. Temperature variation $\theta(Y)$ under the influence of $\Lambda$. 


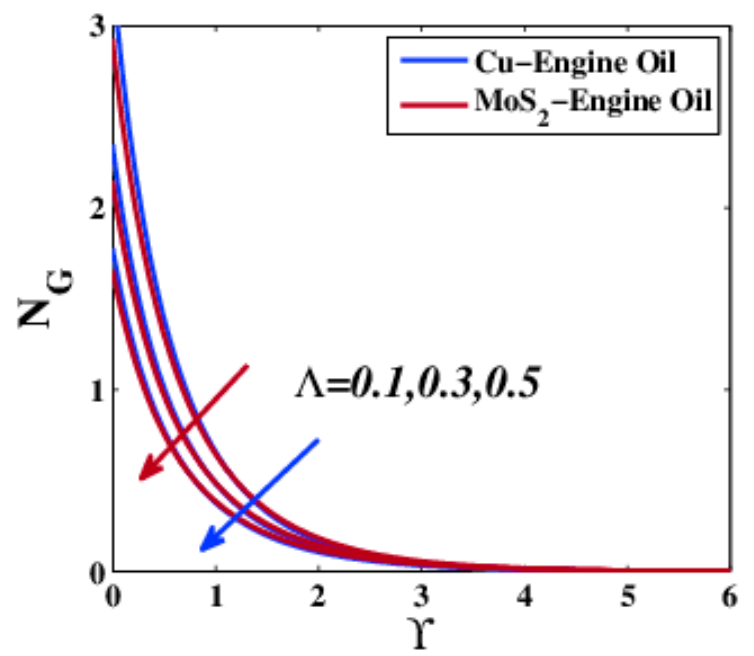

Figure 18. Entropy generation variation $N_{G}$ under the influence of $\Lambda$.

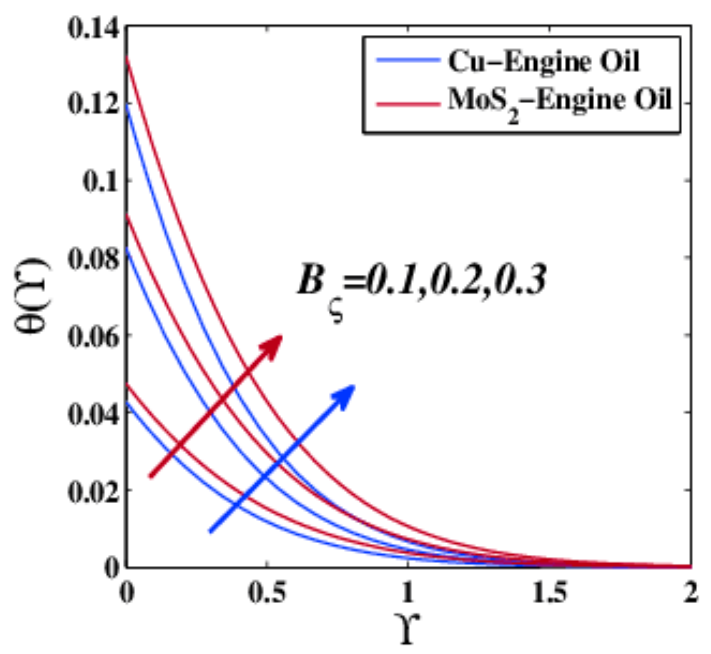

Figure 19. Temperature variation $\theta(Y)$ under the influence of $B_{\zeta}$.

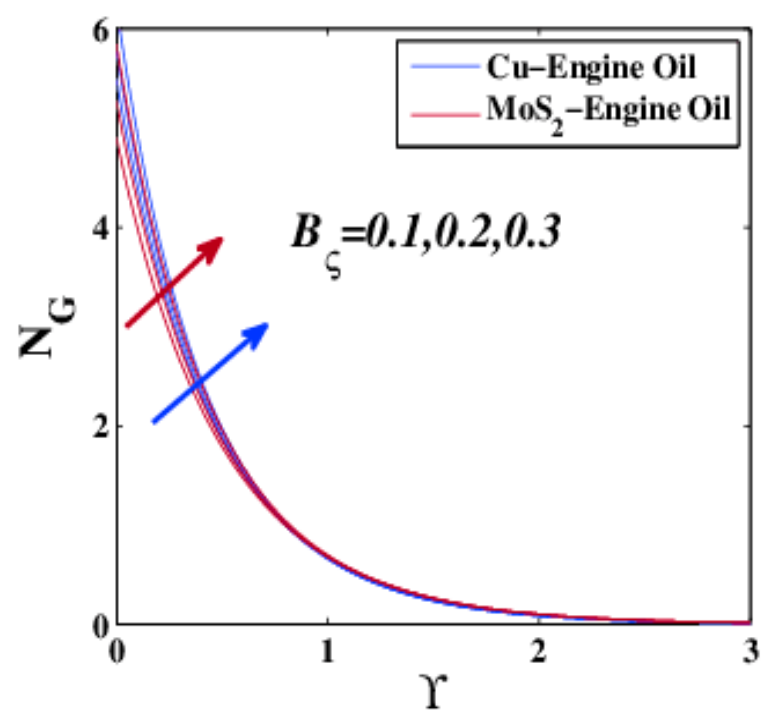

Figure 20. Entropy generation variation $N_{G}$ under the influence of $B_{\zeta}$. 


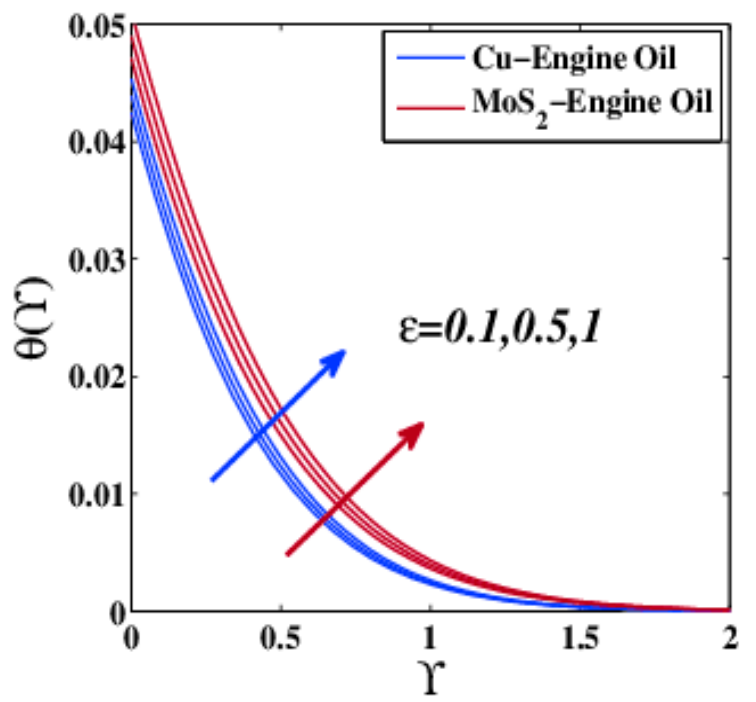

Figure 21. Temperature variation $\theta(Y)$ under the influence of $\varepsilon$.

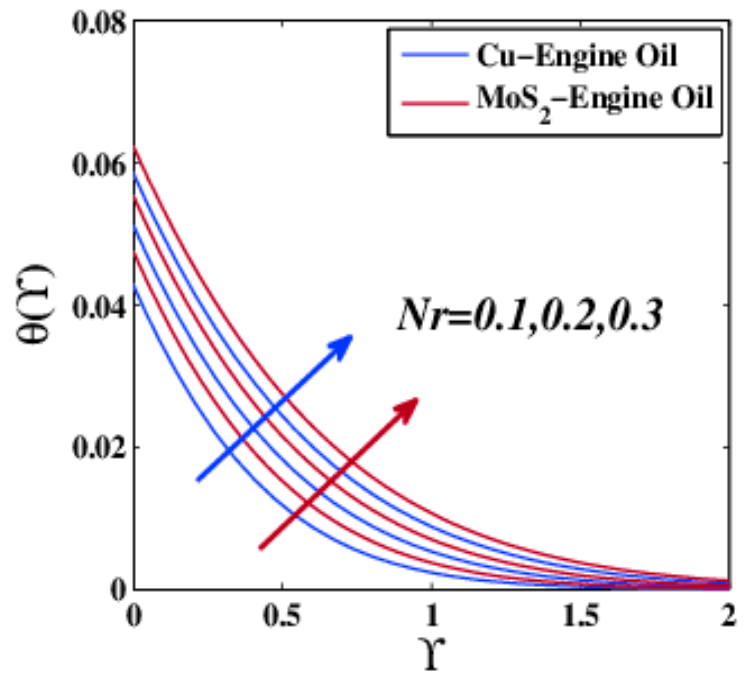

Figure 22. Temperature variation $\theta(Y)$ under the influence of $N r$.

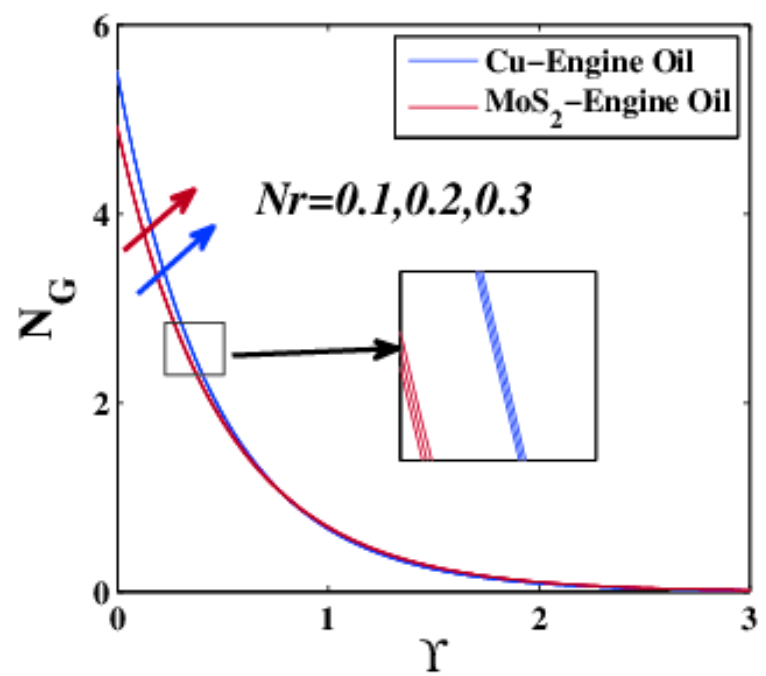

Figure 23. Entropy generation variation $N_{G}$ under the influence of $N r$. 


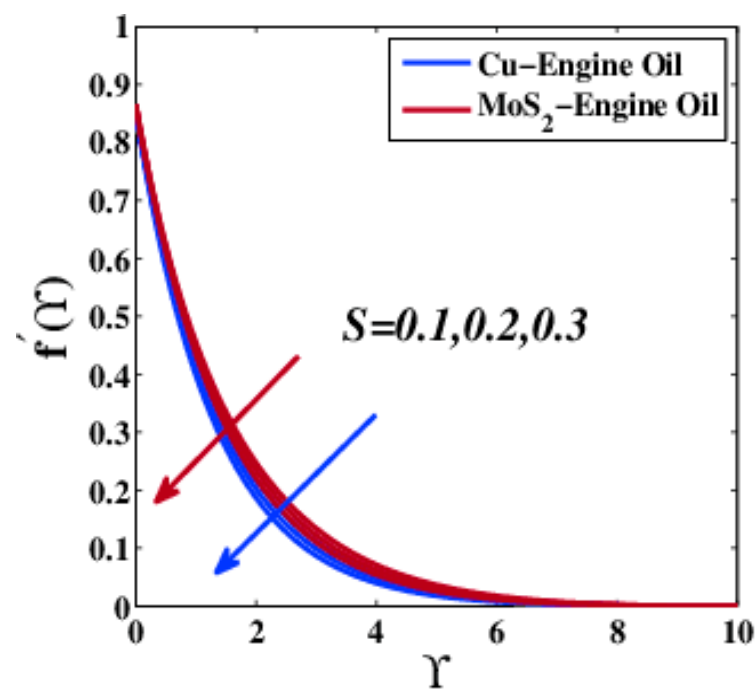

Figure 24. Velocity variation $f^{\prime}(Y)$ under the influence of $S>0$.

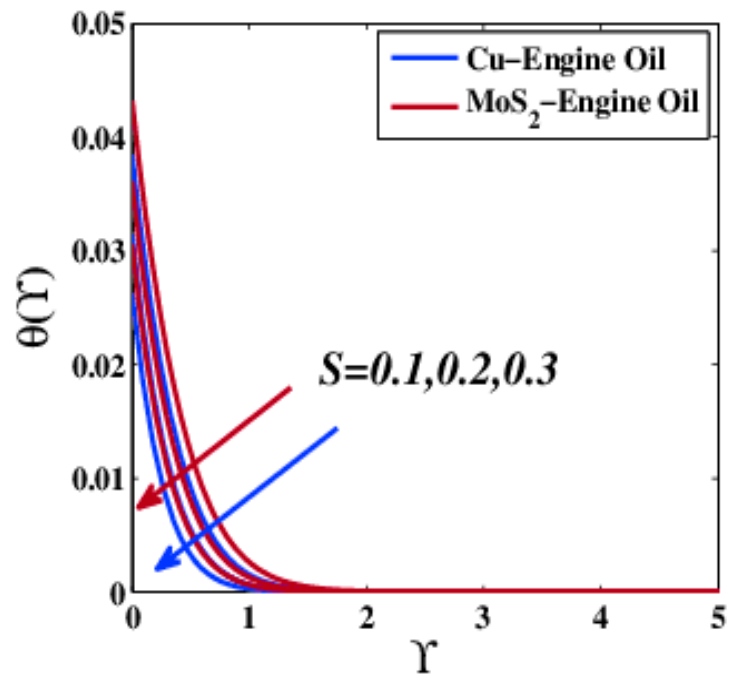

Figure 25. Temperature variation $\theta(Y)$ under the influence of $S>0$.

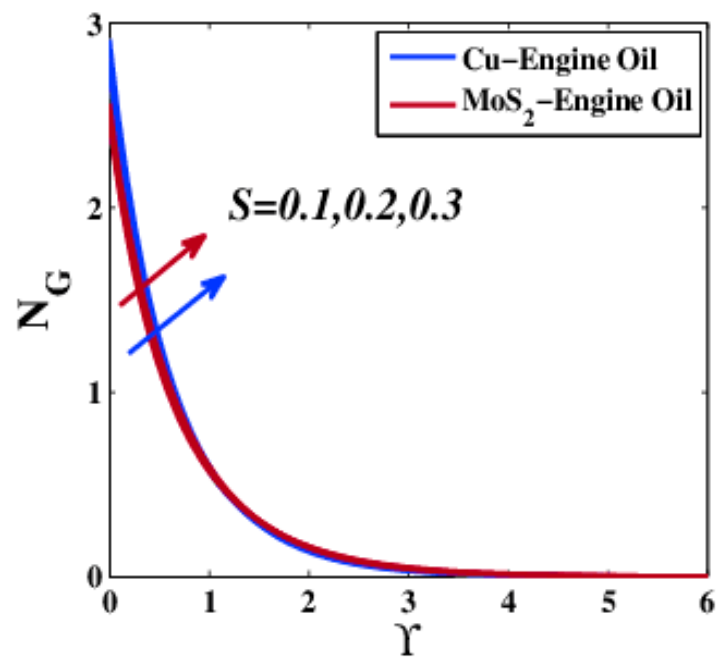

Figure 26. Entropy generation variation $N_{G}$ under the influence of $S>0$. 


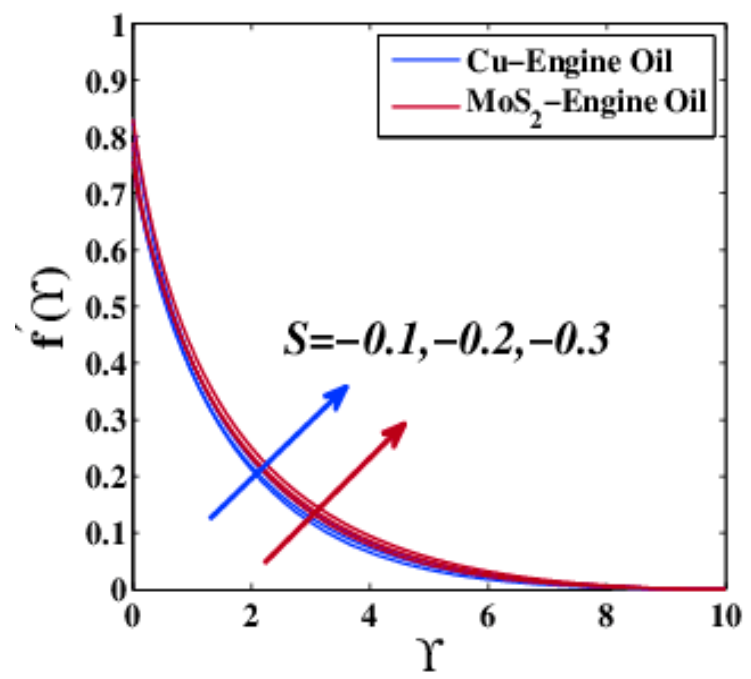

Figure 27. Velocity variation $f^{\prime}(Y)$ under the influence of $S<0$.

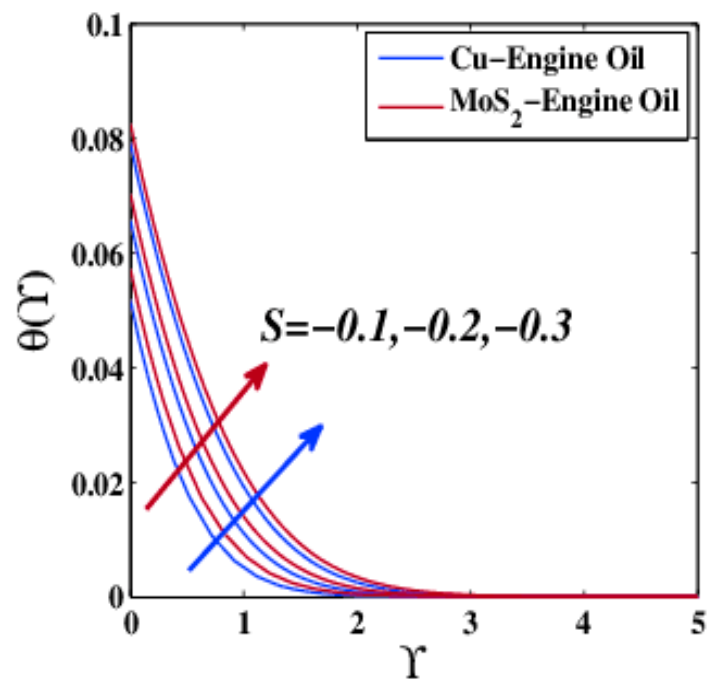

Figure 28. Temperature variation $\theta(Y)$ under the influence of $S<0$.

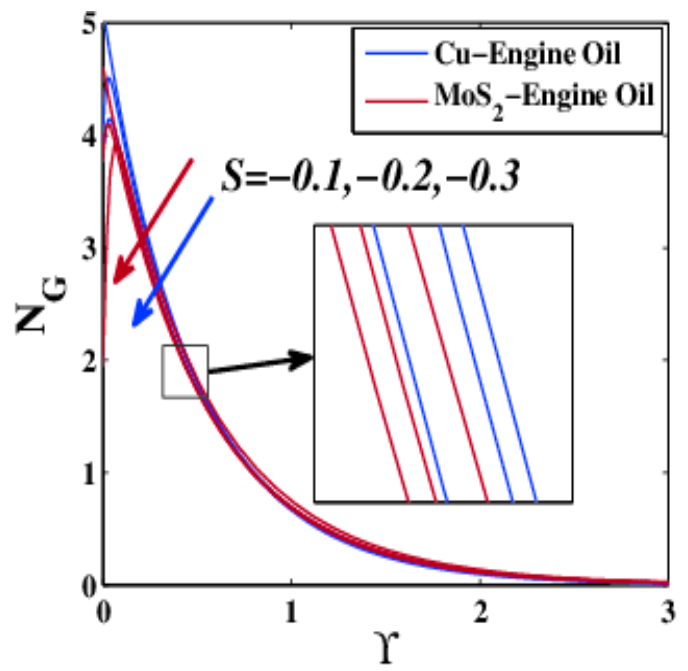

Figure 29. Entropy variation $N_{G}$ under the influence of $S<0$. 


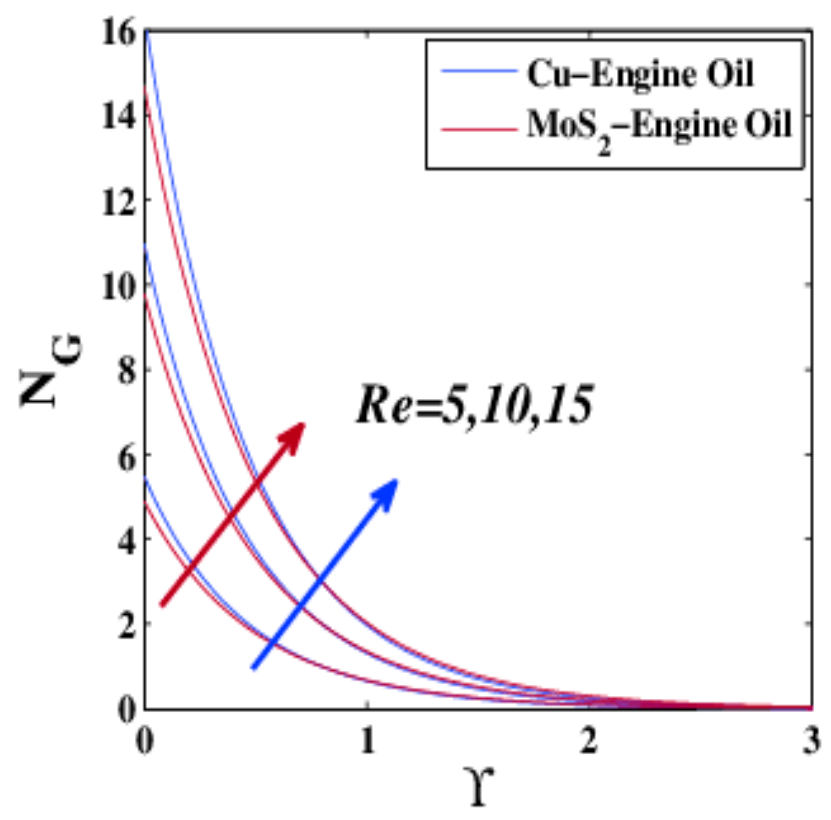

Figure 30. Entropy generation variation $N_{G}$ under the influence of $R e$.

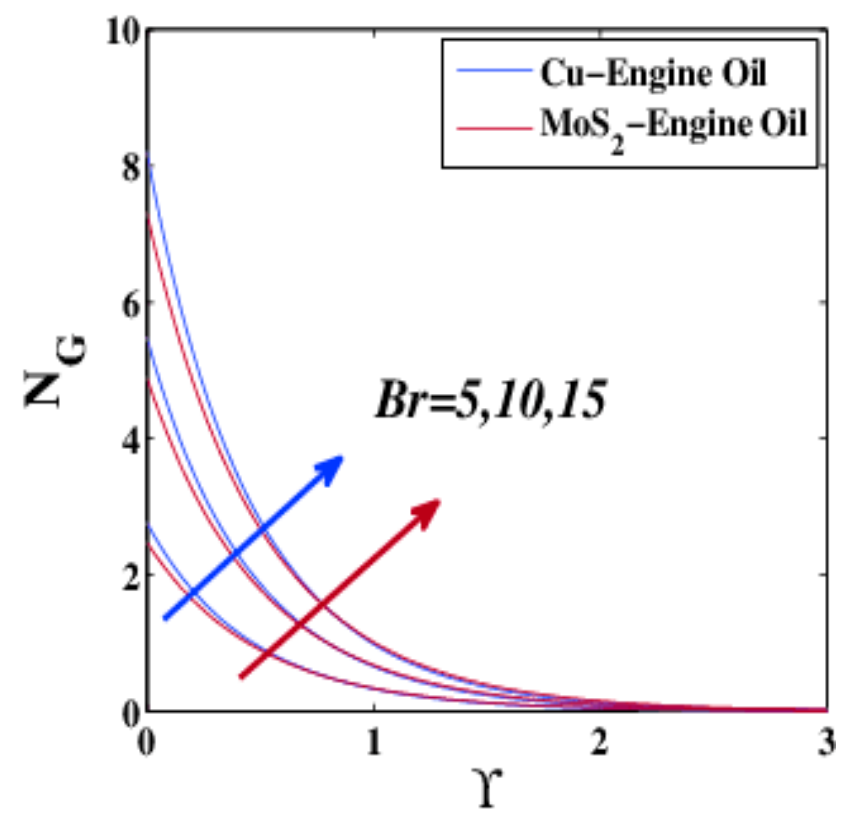

Figure 31. Entropy generation variation $N_{G}$ under the influence of $B r$.

Figures 10-12 show the impact of porous media parameter $K$ on the variations of velocity, temperature, and entropy generation. The porous media parameter indicates the absorption rate of the fluid when passing through pores. Since a hybrid nanofluid contains more than one type of nanometer-sized particles, the absorption rate becomes slower, as shown in Figure 10. However, the role of porous media parameter $K$ is to increase the values of temperature (Figure 11) and entropy generation (Figure 12).

The impact of nanosolid particle size factor $\phi$ on the variations of velocity (Figure 13), temperature (Figure 14), and entropy generation (Figure 15) are depicted against boundary layer thickness $Y$. The parameter $\phi$ causes an increase in the variations of temperature $\theta(Y)$ and entropy generation $N_{G}$ because an increment in $\phi$ causes the density of the nanofluid to increase. As a result, two effects co-occur: (a) a decreasing simultaneous velocity and (b) an increasing thermal conductivity and simultaneous temperature. 
The graphical representations of velocity slip parameter $\Lambda$ can be seen in Figures 16-18. These three figures display the variations of velocity, temperature, and entropy generation. The effect of the velocity slip factor is to decrease the values of velocity and entropy generation profiles. However, this parameter causes the temperature profile to increase because an increase in the slip factor produces frictional force, and the fluid velocity is reduced. Nevertheless, this slip parameter causes the temperature to shift upward.

Figures 19 and 20 show that the effect of the Biot number $B_{\varsigma}$ is to increase the variations of temperature $\theta(Y)$ and entropy generation $N_{G}$. The Biot number is defined as a dimensionless number related to the convective boundary condition. Therefore, Figure 19 shows that the temperature profile and thermal boundary layer thickness are increased due to the effect of the Biot number. Moreover, the Biot number causes an enhancement in heat transfer rate. Thus, the entropy generation is also increased (Figure 20). The impact of variable thermal conductivity $\varepsilon$ on temperature profiles can be seen in Figure 21 . When the thermal conductivity increases, the thermal boundary layer thickness increases, and the hybrid nanofluid's temperature rises. Meanwhile, the radiation parameter $N r$ causes the temperature and entropy generation variations to be improved (Figures 22 and 23, respectively). The radiation parameter is defined as the thermal radiation transfer divided by the conduction heat transfer. A higher amount of heat energy flows into the system is indicated by higher values of $N r$. As a result, the temperature profile shifts upward.

The representation of the suction parameter and injection parameter is demonstrated in Figures 24-26, and Figures 27-29, respectively. The velocity profile under the influence of the suction parameter is depicted in Figure 24. Meanwhile, the same profile with the effect of the injection parameter is presented in Figure 27. Moreover, the temperature profiles due to the suction and injection parameters are depicted in Figures 25 and 28, respectively. Figures 26 and 29 show the entropy generation profiles against the variations of suction and injection parameters, respectively. The swiftness and temperature outlines are suppressed by the increment of the suction parameter, whereas the same parameter causes the entropy generation parameter to rise. This situation can be explained by the presence of suction causing the heated fluid to flow towards the sheet. Consequently, the buoyancy force slows down the fluid velocity due to the high viscosity. Instantaneously, the temperature is reduced, and the entropy generation increases. However, the opposite pattern has been observed for the same profiles when increasing the injection parameter. The role of the injection parameter is to give an opposite effect on the direction of heated fluid and buoyancy force. Hence, the effect of the injection parameter on all the outlines shows the reverse trend compared to the suction parameter.

The impact of the Reynolds number $\mathrm{Re}$ and the Brinkman number $\mathrm{Br}$ on entropy production $N_{G}$ are offered in Figures 30 and 31, respectively. These figures show that $N_{G}$ increases as $\mathrm{Re}$ and $\mathrm{Br}$ increase. The Reynolds number is defined as the ratio of inertial forces (frictional forces) to viscous forces. The augmentation of the Reynolds number causes the enhancement of the following: frictional force at the fluid, heat, and mass transfer. Consequently, entropy production is produced. In addition, the increase of $\mathrm{Br}$ causes an increase in the rate of viscous dissipation. The Brinkman number $\mathrm{Br}$ is defined as the ratio between heat produced by viscous dissipation and heat transported by molecular conduction. This number is also known as a ratio of viscous heat generation to external heating. As a result, entropy generation $N_{G}$ is enhanced due to the change in viscous dissipation.

The numerical results of the local Nusselt number $=N_{u} \operatorname{Re}_{x}^{\frac{-1}{2}}$ for various values of $B_{\zeta}$, $\Lambda, S>0, \phi, N r$, and $\operatorname{Pr}$ are observed in Table 4. From this table, it is shown that the effect of $B_{\zeta}, S>0, N r$, and $\operatorname{Pr}$ are to enhance the wall heat flux $N_{u} R e_{x}^{\frac{-1}{2}}$ for both $\mathrm{Cu}-\mathrm{EO}$ and $\mathrm{MoS}_{2}-\mathrm{EO}$ nanofluids. In addition, $N_{u} \operatorname{Re}_{x}^{\frac{-1}{2}}$ for both $\mathrm{Cu}-\mathrm{EO}$ and $\mathrm{MoS}_{2}-\mathrm{EO}$ is reduced due to the increment of $\Lambda$. However, the effect of $\phi$ is to reduce the rate of $N_{u} R e_{x}^{\frac{-1}{2}}$ for $\mathrm{Cu}-\mathrm{EO}$ and to increase the local Nusselt number $N_{u} \operatorname{Re}_{x}^{\frac{-1}{2}}$ for $\mathrm{MoS}_{2}-\mathrm{EO}$. 
Table 4. Calculations of the Nusselt number $=N_{u} R e_{x}^{\frac{-1}{2}}$ for $\operatorname{Pr}=6450$.

\begin{tabular}{|c|c|c|c|c|c|c|c|c|}
\hline$B_{\zeta}$ & $\Lambda$ & $S$ & $\phi$ & $N r$ & $\operatorname{Pr}$ & $\begin{array}{l}N_{u} R e_{x}^{\frac{-1}{2}} \\
\mathrm{Cu}-\mathrm{EO}\end{array}$ & $\begin{array}{c}N_{u} R e_{x}^{\frac{-1}{2}} \\
\operatorname{MoS}_{2}-\mathrm{EO}\end{array}$ & $\begin{array}{c}\text { Relative\% } \\
\frac{\left.N u_{(\mathrm{Cu})}-N u_{(\mathrm{Mos})}\right)}{N u_{(\mathrm{Cu})}} \times 100\end{array}$ \\
\hline 0.1 & 0.2 & 0.1 & 0.1 & 0.3 & 0.2 & 0.0907 & 0.1209 & $25 \%$ \\
\hline 0.2 & & & & & & 0.1735 & 0.2302 & $26 \%$ \\
\hline \multirow[t]{16}{*}{0.3} & & & & & & 0.2492 & 0.3291 & $27 \%$ \\
\hline & 0.1 & & & & & 0.0909 & 0.1212 & $24 \%$ \\
\hline & 0.2 & & & & & 0.0907 & 0.1209 & $23 \%$ \\
\hline & 0.3 & & & & & 0.0905 & 0.1207 & $22 \%$ \\
\hline & & 0.1 & & & & 0.0911 & 0.6010 & $29 \%$ \\
\hline & & 0.2 & & & & 0.0915 & 0.1219 & $28 \%$ \\
\hline & & 0.3 & & & & 0.0920 & 0.1225 & $27 \%$ \\
\hline & & & 0.01 & & & 0.1100 & 0.1079 & $1.9 \%$ \\
\hline & & & 0.05 & & & 0.0980 & 0.1209 & $20 \%$ \\
\hline & & & 0.1 & & & 0.0852 & 0.1388 & $40 \%$ \\
\hline & & & & 0.1 & & 0.0857 & 0.1400 & $38 \%$ \\
\hline & & & & 0.2 & & 0.0920 & 0.1513 & $39 \%$ \\
\hline & & & & 0.3 & & 0.0982 & 0.1625 & $39 \%$ \\
\hline & & & & & 10 & 0.0857 & 0.1513 & $41 \%$ \\
\hline & & & & & 15 & 0.0859 & 0.1519 & $42 \%$ \\
\hline & & & & & 20 & 0.0860 & 0.1523 & $43 \%$ \\
\hline
\end{tabular}

\section{Final Outcomes}

The numerical solutions are controlled by the following parameters: the first component of Deborah number $\beta_{1}$, second component of Deborah number $\beta_{2}$, porous media parameter $K$, volume friction parameter $\phi$, velocity slip parameter $\Lambda$, Biot number $B_{\zeta}$, variable thermal conductivity $\varepsilon$, radiation parameter $N r$, suction parameter $S>0$, injection parameter $S<0$, Reynolds number Re, and Brinkman number $B r$. The previous section showed that the effect of the related parameters on the variations of velocity, temperature, and entropy generation was valid for both $\mathrm{Cu}-\mathrm{EO}$ and $\mathrm{MoS}_{2}-\mathrm{EO}$. As a result, the main findings of this paper are summarized below:

(a) An increase in velocity distribution was observed, under the influence of $\beta_{2}$ and $S>0$. Otherwise, this profile decreased due to the increase of $\beta_{1}, K, \phi, \Lambda$ and $S>0$.

(b) The velocity of molybdenum disulfide engine oil $\left(\mathrm{MoS}_{2}-\mathrm{EO}\right)$ nanofluid was found to be higher than copper engine oil $(\mathrm{Cu}-\mathrm{EO})$ nanofluid. This comparison was depicted under the impact of the Deborah number, porous media parameter, nanoparticle volume fraction parameter, velocity slip parameter, suction, and injection.

(c) The fluid temperature increased due to increasing values of $\beta_{1}, K, \phi, \Lambda, B_{\zeta}, \varepsilon, N r$, and $S<0$. However, the same profile decreased due to $\beta_{2}$ and $S>0$.

(d) Temperature profiles showed that the graphs for $\mathrm{MoS}_{2}-\mathrm{EO}$ were above those for the $\mathrm{Cu}-\mathrm{EO}$ nanofluid. These two lines can be observed when varying controlling parameters such as the Deborah number, porous media parameter, velocity slip parameter, Biot number, variable thermal conductivity, radiation parameter, suction, and injection. However, the temperature measured for the $\mathrm{Cu}-\mathrm{EO}$ nanofluid was greater than for $\mathrm{MoS}_{2}-\mathrm{EO}$, for various values of the nanoparticle volume fraction parameter.

(e) The roles of Deborah number $\left(\beta_{1}\right.$ and $\left.\beta_{2}\right)$, velocity slip parameter, and injection parameter were to lessen the values of entropy generation. At the same time, this profile was enhanced when the following parameters increased: porous media parameter, volume friction parameter, Biot number, radiation parameter, suction parameter, Reynolds number, and Brinkman number.

(f) At the small thickness boundary layer, the entropy generation of $\mathrm{MoS}_{2}-\mathrm{EO}$ was higher than that of $\mathrm{Cu}-\mathrm{EO}$ when this profile was affected by Deborah number. Moreover, $\mathrm{Cu}-\mathrm{EO}$ entropy generation was greatest for increasing series of porous media parameter, nanoparticle volume fraction parameter, velocity slip parameter, Biot number, radiation parameter, suction, injection, Reynolds number, and Brinkman number. 
(g) The local Nusselt number was an ascending function of $B_{\zeta}, S>0, N r$, and $P r$. Moreover, the local Nusselt number was a decreasing function of $\Lambda$. The effects of $B_{\zeta}$, $S>0, N r, P r$, and $\Lambda$ are valid for both $\mathrm{Cu}-\mathrm{EO}$ and $\mathrm{MoS}_{2}-\mathrm{EO}$. However, the effect of $\phi$ on the local Nusselt number was described as follows: (i) decrease for $\mathrm{Cu}-\mathrm{EO}$; (ii) increase for $\mathrm{MoS}_{2}-\mathrm{EO}$.

\section{Future Direction}

In this work, we have employed the concept of entropy generation analysis and the effects of slip conditions on fluid flow. One can replace Equation (21) with another formula of entropy. For example, we suggest considering a fractional entropy such as the Tsallis entropy.

Author Contributions: Conceptualization, F.S., W.J. and M.R.E.; methodology, F.S., W.J. and M.R.E.; software, F.S., W.J., R.W.I., K.S.N., M.A.Q. and M.R.E.; validation, F.S., W.J., S.S.P.M.I., A.-H.A.-A. and M.R.E.; formal analysis, F.S., W.J., K.S.N. and M.R.E.; investigation, F.S., W.J., R.W.I., S.S.P.M.I. and M.R.E.; resources, F.S., W.J. and M.R.E.; data curation, F.S., W.J., K.S.N., S.M.H. and M.R.E.; writingoriginal draft preparation, F.S., W.J., A.-H.A.-A. and M.R.E.; writing—review and editing, F.S., W.J., R.W.I., K.S.N., S.M.H., S.S.P.M.I., A.-H.A.-A. and M.R.E.; visualization, F.S., W.J. and M.R.E.; funding acquisition, I.S.Y. All authors have read and agreed to the published version of the manuscript.

Funding: The authors express their appreciation to the Deanship of Scientific Research at King Khalid University for funding this work through research groups program under grant number R.G.P. $2 / 61 / 40$.

Institutional Review Board Statement: Not applicable.

Informed Consent Statement: Not applicable.

Data Availability Statement: The authors confirm that the data supporting the findings of this study are available within the article.

Conflicts of Interest: The authors declare that there is no conflict of interest.

\section{Nomenclatures}

$b \quad$ initial stretching rate

$B_{\varsigma} \quad$ Biot number

$B_{r} \quad$ Brinkman number

$C_{f} \quad$ skin friction coefficient

$C_{p} \quad$ specific heat $\left(\mathrm{J} \mathrm{kg}^{-1} \mathrm{~K}^{-1}\right)$

$E_{G} \quad$ dimensional entropy $(\mathrm{J} / \mathrm{K})$

$h \quad$ Heat transfer coefficient

$\kappa$

K

$k^{*}$

$\epsilon$

$N_{r}$

$N_{G}$

$N u_{x}$

$P_{r}$

$q_{r}$

$q_{w}$

$R_{e}$

$S$

$v_{1}, v_{2}$

$U_{w}$

$V_{w}$

$x, y$ thermal conductivity $\left(\mathrm{W} \mathrm{m}^{-1} \mathrm{~K}^{-1}\right)$

porous medium

absorption coefficient

variable thermal conductivity

radiation parameter

dimensionless entropy generation

local Nusselt number

Prandtl number $(\nu / \alpha)$

radiative heat flux

wall heat flux

Reynolds number

suction/injection parameter

velocity component $\left(\mathrm{m} \mathrm{s}^{-1}\right)$

stretching velocity $\left(\mathrm{m} \mathrm{s}^{-1}\right)$

vertical velocity $\left(\mathrm{m} \mathrm{s}^{-1}\right)$

dimensional space coordinates $(\mathrm{m})$
Greek Symbols

$¥ \quad$ fluid temperature (K)

$¥_{w} \quad$ fluid temperature of the surface (K)

$¥_{\infty} \quad$ ambient temperature (K)

$\phi \quad$ volume fraction of the nanoparticles

$\rho \quad$ density $\left(\mathrm{kg} \mathrm{m}^{-3}\right)$

$\sigma^{*} \quad$ Stefan-Boltzmann constant

$\psi \quad$ stream function

$\gamma \quad$ independent similarity variable

$\theta \quad$ dimensionless temperature

$\Lambda \quad$ velocity slip

$\mu \quad$ dynamic viscosity $\left(\mathrm{kg} \mathrm{m}^{-1} \mathrm{~s}^{-1}\right)$

$v \quad$ kinematic viscosity $\left(\mathrm{m}^{2} \mathrm{~s}^{-1}\right)$

$\alpha \quad$ thermal diffusivity $\left(\mathrm{m}^{2} \mathrm{~s}^{-1}\right)$

$\beta_{1} \quad$ Deborah number-I

$\beta_{2} \quad$ Deborah number-II

$\Omega \quad$ dimensionless temperature gradient

Subscripts

$f \quad$ base fluid

$s \quad$ particles

nf nanofluid 


\section{Appendix A. In This Part, We Give the Details of the Numerical Procedure for the Keller-Box Method}

Appendix A.1. Difference Equations

The domain $[0,1]$ has been converted into subdomains utilizing a regular mesh with the subsequent grid points:

$\mathrm{Y}_{0}=0, \mathrm{Y}_{j}=\mathrm{Y}_{j-1}+\Delta h_{j}, j=0,1,2,3 \ldots, J, \mathrm{Y}_{J}=1$, where $\Delta h_{j}$ is the step-size. First-order ODES (21)-(26) have been estimated with the aid of central differences at the midpoint $Y_{j-1 / 2}$, as follows:

$$
\left.\begin{array}{c}
\left(G v_{1}\right)_{j}-\left(G v_{1}\right)_{j-1}=0.5 \Delta h_{j}\left(\left(G v_{2}\right)_{j}+\left(G v_{2}\right)_{j-1}\right), \\
\left(G v_{2}\right)_{j}-\left(G v_{2}\right)_{j-1}=0.5 \Delta h_{j}\left(\left(G v_{3}\right)_{j}+\left(G v_{3}\right)_{j-1}\right), \\
\left(G v_{3}\right)_{j}-\left(G v_{3}\right)_{j-1}=0.5 \Delta h_{j}\left(\left(G v_{4}\right)_{j}+\left(G v_{4}\right)_{j-1}\right), \\
\left(G v_{5}\right)_{j}-\left(G v_{5}\right)_{j-1}=0.5 \Delta h_{j}\left(\left(G v_{6}\right)_{j}+\left(G v_{6}\right)_{j-1}\right), \\
-\beta_{2} \frac{\left(\left(G v_{1}\right)_{j}+\left(G v_{1}\right)_{j-1}\right)}{2}\left(\left(G v_{4}\right)_{j}-\left(G v_{4}\right)_{j-1}\right)+\Delta h_{j} \beta_{2} \frac{\left(\left(G v_{3}\right)_{j}+\left(G v_{3}\right)_{j-1}\right)^{2}}{4} \\
+\Delta h_{j} \phi_{a} \phi_{b} \frac{\left(\left(G v_{1}\right)_{j}+\left(G v_{1}\right)_{j-1}\right)}{2} \frac{\left(\left(G v_{3}\right)_{j}+\left(G v_{3}\right)_{j-1}\right)}{2}-\phi_{a} \phi_{b} \frac{\left(\left(G v_{2}\right)_{j}+\left(G v_{2}\right)_{j-1}\right)^{2}}{4} \\
+2 \Delta h_{j} \phi_{a} \phi_{b} \beta_{1} \frac{\left(\left(G v_{1}\right)_{j}+\left(G v_{1}\right)_{j-1}\right)}{2} \frac{\left(\left(G v_{2}\right)_{j}+\left(G v_{2}\right)_{j-1}\right)}{2}-\Delta h_{j} \phi_{a} \phi_{b} \beta_{1} \frac{\left(\left(G v_{1}\right)_{j}+\left(G v_{1}\right)_{j-1}\right)^{2}}{4} \\
\frac{\left(\left(G v_{4}\right)_{j}+\left(G v_{4}\right)_{j-1}\right)}{2}-\frac{\Delta h_{j}}{\phi_{a}} K \frac{\left(\left(G v_{2}\right)_{j}+\left(G v_{2}\right)_{j-1}\right)}{2}+\Delta h_{j} \frac{\left(\left(G v_{4}\right)_{j}+\left(G v_{4}\right)_{j-1}\right)}{2}=0, \\
\left(\left(G v_{6}\right)_{j}-\left(G v_{6}\right)_{j-1}\right)+\epsilon \frac{\left(\left(G v_{5}\right)_{j}+\left(G v_{5}\right)_{j-1}\right)}{2}\left(\left(G v_{6}\right)_{j}-\left(G v_{6}\right)_{j-1}\right) \\
+\frac{1}{\phi_{d}} \operatorname{PrNr}\left(\left(G v_{6}\right)_{j}-\left(G v_{6}\right)_{j-1}\right)+\Delta h_{j} \epsilon \frac{\left(\left(G v_{6}\right)_{j}+\left(G v_{6}\right)_{j-1}\right)^{2}}{4} \\
+\Delta h_{j} \operatorname{Pr} \frac{\phi_{c}}{\phi_{d}} \frac{\left(\left(G v_{1}\right)_{j}+\left(G v_{1}\right)_{j-1}\right)}{2} \frac{\left(\left(G v_{6}\right)_{j}+\left(G v_{6}\right)_{j-1}\right)}{2} \\
-\Delta h_{j} \operatorname{Pr} \frac{\phi_{c}}{\phi_{d}} \frac{\left(\left(G v_{2}\right)_{j}+\left(G v_{2}\right)_{j-1}\right)}{2} \frac{\left(\left(G v_{5}\right)_{j}+\left(G v_{5}\right)_{j-1}\right)}{2}=0,
\end{array}\right\},
$$

Appendix A.2. Newton Linearization

The above system of Equations (A1)-(A6) is linearized by Newton's linearization method using the following substitution:

$$
\left.\begin{array}{rl}
\left(G v_{1}\right)_{j}^{n+1}=\left(G v_{1}\right)_{j}^{n}+\left(\delta G_{1}\right)_{j}^{n},\left(G v_{2}\right)_{j}^{n+1} & =\left(G v_{2}\right)_{j}^{n}+\left(\delta G_{2}\right)_{j}^{n}, \\
\left(G v_{3}\right)_{j}^{n+1}=\left(G v_{3}\right)_{j}^{n}+\left(\delta G v_{3}\right)_{j}^{n},\left(G v_{4}\right)_{j}^{n+1} & =\left(G v_{4}\right)_{j}^{n}+\left(\delta G v_{4}\right)_{j}^{n}, \\
\left(G v_{5}\right)_{j}^{n+1}=\left(G v_{5}\right)_{j}^{n}+\left(\delta G v_{5}\right)_{j}^{n},\left(G v_{6}\right)_{j}^{n+1}=\left(G v_{6}\right)_{j}^{n}+\left(\delta G v_{6}\right)_{j}^{n} .
\end{array}\right\}
$$

Substituting the expressions obtained in (A1)-(A6) and dropping the square and higher powers of $\delta$, the following set of equations is achieved:

$$
\begin{gathered}
\left(\left(\delta G_{1}\right)_{j}-\left(\delta G_{1}\right)_{j-1}\right)-0.5 \Delta h_{j}\left(\left(\delta G_{2}\right)_{j}+\left(\delta G_{2}\right)_{j-1}\right)=\left(r_{1}\right)_{j}, \\
\left(\left(\delta G_{2}\right)_{j}-\left(\delta G_{2}\right)_{j-1}\right)-0.5 \Delta h_{j}\left(\left(\delta G v_{3}\right)_{j}+\left(\delta G v_{3}\right)_{j-1}\right)=\left(r_{2}\right)_{j}, \\
\left(\left(\delta G v_{3}\right)_{j}-\left(\delta G v_{3}\right)_{j-1}\right)-0.5 \Delta h_{j}\left(\left(\delta G v_{4}\right)_{j}+\left(\delta G v_{4}\right)_{j-1}\right)=\left(r_{3}\right)_{j}, \\
\left(\left(\delta G v_{5}\right)_{j}-\left(\delta G v_{5}\right)_{j-1}\right)-0.5 \Delta h_{j}\left(\left(\delta G v_{6}\right)_{j}+\left(\delta G v_{6}\right)_{j-1}\right)=\left(r_{4}\right)_{j},
\end{gathered}
$$

$\left(\pi_{1}\right)_{j}\left(\delta G_{1}\right)_{j}+\left(\pi_{2}\right)_{j}\left(\delta G_{1}\right)_{j-1}+\left(\pi_{3}\right)_{j}\left(\delta G_{2}\right)_{j}+\left(\pi_{4}\right)_{j}\left(\delta G_{2}\right)_{j-1}+\left(\pi_{5}\right)_{j}\left(\delta G v_{3}\right)_{j}+\left(\pi_{6}\right)_{j}\left(\delta G v_{3}\right)_{j-1}+\left(\pi_{7}\right)_{j}\left(\delta G v_{4}\right)_{j}+\left(\pi_{8}\right)_{j}\left(\delta G v_{4}\right)_{j-1}=\left(r_{5}\right)_{j^{\prime}}$ 
where:

$$
\begin{aligned}
& \left(\pi_{1}\right)_{j}=-\Delta h_{j} \phi_{a} \phi_{b} \beta_{1} \frac{\left(\left(G v_{1}\right)_{j}+\left(G v_{1}\right)_{j-1}\right)\left(\left(G v_{4}\right)_{j}+\left(G v_{4}\right)_{j-1}\right)}{4}=\left(\pi_{2}\right)_{j} \text {, } \\
& \left(\pi_{3}\right)_{j}=-\frac{K \Delta h_{j}}{2 \phi_{a}}+2 \Delta h_{j} \phi_{a} \phi_{b} \beta_{1} \frac{\left(\left(G v_{1}\right)_{j}+\left(G v_{1}\right)_{j-1}\right)}{4}+\Delta h_{j} \phi_{a} \phi_{b} \frac{\left(\left(G v_{2}\right)_{j}+\left(G v_{2}\right)_{j-1}\right)}{2}=\left(\pi_{4}\right)_{j} \text {, } \\
& \left(\pi_{5}\right)_{j}=\Delta h_{j} \phi_{a} \phi_{b} \frac{\left(\left(G v_{1}\right)_{j}+\left(G v_{1}\right)_{j-1}\right)}{4}+\Delta h_{j} \beta_{2} \frac{\left(\left(G v_{3}\right)_{j}+\left(G v_{3}\right)_{j-1}\right)}{2}=\left(\pi_{6}\right)_{j} \text {, } \\
& \left(\pi_{7}\right)_{j}=\frac{\Delta h_{j}}{2}-\beta_{2} \frac{\left(\left(G v_{1}\right)_{j}+\left(G v_{1}\right)_{j-1}\right)}{2}-8 \Delta h_{j} \phi_{a} \phi_{b} \beta_{1}\left(\left(G v_{1}\right)_{j}+\left(G v_{1}\right)_{j-1}\right)^{2}=\left(\pi_{8}\right)_{j} \text {, } \\
& \left(r_{5}\right)_{j}=\beta_{2} \frac{\left(\left(G v_{1}\right)_{j}+\left(G v_{1}\right)_{j-1}\right)}{2}\left(\left(G v_{4}\right)_{j}-\left(G v_{4}\right)_{j-1}\right)-\Delta h_{j} \beta_{2} \frac{\left(\left(G v_{3}\right)_{j}+\left(G v_{3}\right)_{j-1}\right)^{2}}{4} \\
& -\Delta h_{j} \phi_{a} \phi_{b} \frac{\left(\left(G v_{1}\right)_{j}+\left(G v_{1}\right)_{j-1}\right)}{2} \frac{\left(\left(G v_{3}\right)_{j}+\left(G v_{3}\right)_{j-1}\right)}{2}-\phi_{a} \phi_{b} \frac{\left(\left(G v_{2}\right)_{j}+\left(G v_{2}\right)_{j-1}\right)^{2}}{4} \\
& -2 \Delta h_{j} \phi_{a} \phi_{b} \beta_{1} \frac{\left(\left(G v_{1}\right)_{j}+\left(G v_{1}\right)_{j-1}\right)}{2} \frac{\left(\left(G v_{2}\right)_{j}+\left(G v_{2}\right)_{j-1}\right)}{2}-\Delta h_{j} \phi_{a} \phi_{b} \beta_{1} \frac{\left(\left(G v_{1}\right)_{j}+\left(G v_{1}\right)_{j-1}\right)^{2}}{4} \\
& \frac{\left(\left(G v_{4}\right)_{j}+\left(G v_{4}\right)_{j-1}\right)}{2}+\frac{\Delta h_{j}}{\phi_{a}} K \frac{\left(\left(G v_{2}\right)_{j}+\left(G v_{2}\right)_{j-1}\right)}{2}-\Delta h_{j} \frac{\left(\left(G v_{4}\right)_{j}+\left(G v_{4}\right)_{j-1}\right)}{2}, \\
& \left(m_{1}\right)_{j}=\Delta h_{j} \frac{P r \phi_{c}}{\phi_{d}} \frac{\left(\left(G v_{6}\right)_{j}+\left(G v_{6}\right)_{j-1}\right)}{4}=\left(m_{2}\right)_{j} \text {, } \\
& \left(m_{3}\right)_{j}=-\Delta h_{j} \frac{P r \phi_{c}}{\phi_{d}} \frac{\left(\left(G v_{6}\right)_{j}+\left(G v_{6}\right)_{j-1}\right)}{4}=\left(m_{4}\right)_{j} \text {, } \\
& \left(m_{5}\right)_{j}=\Delta h_{j} \frac{P r \phi_{c}}{\phi_{d}} \frac{\left(\left(G v_{2}\right)_{j}+\left(G v_{2}\right)_{j-1}\right)}{4}+\epsilon \frac{\left(\left(G v_{6}\right)_{j}-\left(G v_{6}\right)_{j-1}\right)}{2}=\left(m_{6}\right)_{j} \text {, } \\
& \left(m_{7}\right)_{j}=1+\frac{N r P r}{\phi_{d}}+\Delta h_{j} \frac{P r \phi_{c}}{\phi_{d}} \frac{\left(\left(G v_{1}\right)_{j}+\left(G v_{1}\right)_{j-1}\right)}{4}+\epsilon \frac{\left(\left(G v_{5}\right)_{j}-\left(G v_{5}\right)_{j-1}\right)}{2} \\
& +\Delta h_{j} \epsilon \frac{\left(\left(G v_{6}\right)_{j}-\left(G v_{6}\right)_{j-1}\right)}{2} \text {, } \\
& \left(m_{8}\right)_{j}=-1-\frac{N r P r}{\phi_{d}}+\Delta h_{j} \frac{P r \phi_{c}}{\phi_{d}} \frac{\left(\left(G v_{1}\right)_{j}+\left(G v_{1}\right)_{j-1}\right)}{4}+\epsilon \frac{\left(\left(G v_{5}\right)_{j}-\left(G v_{5}\right)_{j-1}\right)}{2} \\
& +\Delta h_{j} \epsilon \frac{\left(\left(G v_{6}\right)_{j}-\left(G v_{6}\right)_{j-1}\right)}{2} \text {, } \\
& \left(r_{6}\right)_{j}=-\left(\left(G v_{6}\right)_{j}-\left(G v_{6}\right)_{j-1}\right)-\epsilon \frac{\left(\left(G v_{5}\right)_{j}+\left(G v_{5}\right)_{j-1}\right)}{2}\left(\left(G v_{6}\right)_{j}-\left(G v_{6}\right)_{j-1}\right) \\
& -\frac{1}{\phi_{d}} \operatorname{PrNr}\left(\left(G v_{6}\right)_{j}-\left(G v_{6}\right)_{j-1}\right)+\Delta h_{j} \epsilon \frac{\left(\left(G v_{6}\right)_{j}+\left(G v_{6}\right)_{j-1}\right)^{2}}{4} \\
& +\Delta h_{j} \operatorname{Pr} \frac{\phi_{c}}{\phi_{d}} \frac{\left(\left(G v_{1}\right)_{j}+\left(G v_{1}\right)_{j-1}\right)}{2} \frac{\left(\left(G v_{6}\right)_{j}+\left(G v_{6}\right)_{j-1}\right)}{2} \\
& +\Delta h_{j} \operatorname{Pr} \frac{\phi_{c}}{\phi_{d}} \frac{\left(\left(G v_{2}\right)_{j}+\left(G v_{2}\right)_{j-1}\right)}{2} \frac{\left(\left(G v_{5}\right)_{j}+\left(G v_{5}\right)_{j-1}\right)}{2},
\end{aligned}
$$

Appendix A.3. Block Tridiagonal Structure

Next, the linearized system has the following block-tridiagonal structure:

$$
A \Delta=S,
$$

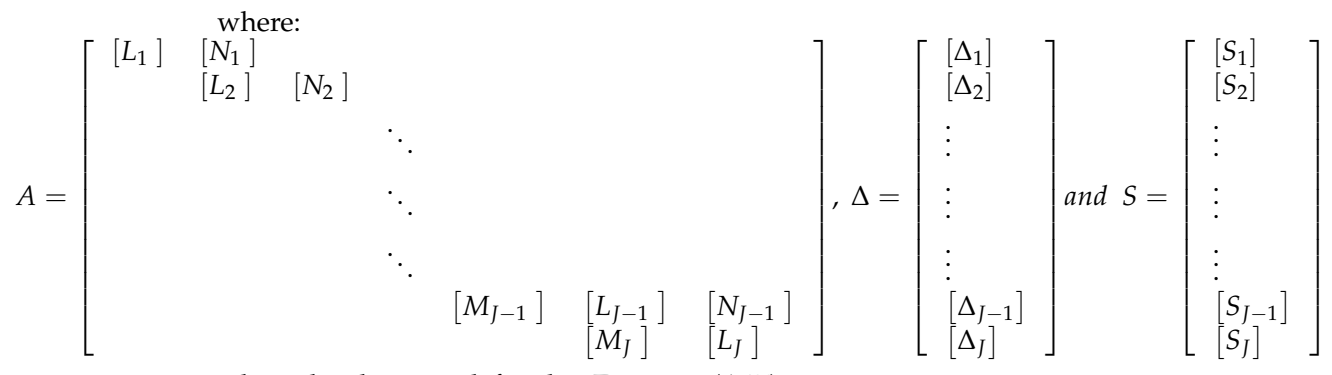

where the elements defined in Equation (A17) are:

$$
\begin{aligned}
& {\left[\begin{array}{ll}
L_{1}
\end{array}\right]=\left[\begin{array}{llllll}
0 & 0 & 0 & 1 & 0 & 0 \\
-0.5 \Delta h_{1} & 0 & 0 & 0 & 0 & 0 \\
-1 & 0 & -0.5 \Delta h_{1} & 0 & -0.5 \Delta h_{1} & 0 \\
0 & -1 & 0 & 0 & 0 & -0.5 \Delta h_{1} \\
\left(\pi_{6}\right)_{1} & 0 & \left(\pi_{8}\right)_{1} & \left(\pi_{1}\right)_{1} & \left(\pi_{7}\right)_{1} & 0 \\
0 & \left(m_{6}\right)_{1} & 0 & \left(m_{1}\right)_{1} & 0 & \left(m_{7}\right)_{1}
\end{array}\right]} \\
& {\left[L_{j}\right]=\left[\begin{array}{llllll}
-0.5 \Delta h_{j} & 0 & 0 & 1 & 0 & 0 \\
-1 & -0.5 \Delta h_{j} & 0 & 0 & 0 & 0 \\
0 & -1 & 0 & 0 & -0.5 \Delta h_{j} & 0 \\
0 & 0 & -1 & 0 & 0 & -0.5 \Delta h_{j} \\
\left(\pi_{4}\right)_{j} & \left(\pi_{6}\right)_{j} & 0 & \left(\pi_{1}\right)_{j} & \left(\pi_{7}\right)_{j} & 0 \\
\left(m_{4}\right)_{j} & 0 & \left(m_{6}\right)_{j} & \left(m_{1}\right)_{j} & 0 & \left(m_{7}\right)_{j}
\end{array}\right], 2 \leq j \leq J}
\end{aligned}
$$




$$
\begin{aligned}
{\left[M_{j}\right] } & =\left[\begin{array}{llllll}
0 & 0 & 0 & -1 & 0 & 0 \\
0 & 0 & 0 & 0 & 0 & 0 \\
0 & 0 & 0 & 0 & -0.5 \Delta h_{j} & 0 \\
0 & 0 & 0 & 0 & 0 & -0.5 \Delta h_{1} \\
0 & 0 & 0 & \left(\pi_{2}\right)_{j} & \left(\pi_{8}\right)_{j} & 0 \\
0 & 0 & 0 & \left(m_{2}\right)_{j} & 0 & \left(m_{8}\right)_{j}
\end{array}\right], 2 \leq j \leq J \\
{\left[N_{j}\right] } & {\left[\begin{array}{llllll}
-0.5 \Delta h_{j} & 0 & 0 & 0 & 0 & 0 \\
1 & -0.5 \Delta h_{j} & 0 & 0 & 0 & 0 \\
0 & 1 & 0 & 0 & 0 & 0 \\
0 & 0 & 1 & 0 & 0 & 0 \\
\left(\pi_{3}\right)_{j} & \left(\pi_{5}\right)_{j} & 0 & 0 & 0 & 0 \\
\left(m_{3}\right)_{j} & 0 & \left(m_{5}\right)_{j} & 0 & 0 & 0 \\
& & & &
\end{array}\right], 1 \leq j \leq J-1 . }
\end{aligned}
$$

Now we factorize $A$ as:

$$
A=L U,
$$

where:

$$
L=\left[\begin{array}{lllll}
{\left[\Gamma_{1}\right]} & & & & \\
& {\left[\Gamma_{2}\right]} & & & \\
& & \ddots & & \\
& & \ddots & {\left[\Gamma_{J-1}\right]} & \\
& & & {\left[Q_{J}\right]} & {\left[\Gamma_{J}\right]}
\end{array}\right], U=\left[\begin{array}{ccccc}
{[I]} & {\left[\alpha_{1}\right]} & & & \\
& {[I]} & {\left[\alpha_{2}\right]} & & \\
& \ddots & \ddots & \\
& & {[I]} & {\left[\alpha_{J-1}\right]} \\
& & & {[I]}
\end{array}\right],
$$

where the total size of the block-tridiagonal matrix $A$ is $J \times J$ with each block size of super vectors is $6 \times 6$ and $[I]$, $\left[\Gamma_{i}\right]$ and $\left[\alpha_{i}\right]$ are the matrices of order 6 . Implementing an $L U$ decomposition algorithm for the solution of $\Delta$.

\section{References}

1. Choi, S. Enhancing thermal conductivity of fluids with nanoparticles, developments, and applications of non-Newtonian flows. In Proceedings of the ASME International Mechanical Engineering Congress and Exposition, American Society of Mechanical Engineering, San Francisco, CA, USA, 12-17 November 1995; Volume 231, pp. 99-106.

2. Kumar, N.; Hirschey, J.; LaClair, T.J.; Gluesenkamp, K.R.; Graham, S. Review of stability and thermal conductivity enhancements for salt hydrates. J. Energy Storage 2019, 24, 100794. [CrossRef]

3. Abo-Elkhair, R.E.; Bhatti, M.M.; Mekheimer, K.S. Magnetic force effects on peristaltic transport of hybrid bio-nanofluid (AuCu nanoparticles) with moderate Reynolds number: An expanding horizon. Int. Commun. Heat Mass Transf. 2021, 123, 105228. [CrossRef]

4. Mandhare, H.; Barai, D.P.; Bhanvase, B.A.; Saharan, V.K. Preparation and thermal conductivity investigation of reduced graphene oxide-ZnO nanocomposite-based nanofluid synthesised by ultrasound-assisted method. Mater. Res. Innov. 2020, 24, 433-441. [CrossRef]

5. Ma, B.; Shin, D.; Banerjee, D. Synthesis and characterization of molten salt nanofluids for thermal energy storage application in concentrated solar power plants-Mechanistic understanding of specific heat capacity enhancement. Nanomaterials 2020, 10, 2266. [CrossRef] [PubMed]

6. Ma, B.; Shin, D.; Banerjee, D. One-step synthesis of molten salt nanofluid for thermal energy storage application-a comprehensive analysis on thermophysical property, corrosion behavior, and economic benefit. J. Energy Storage 2021, 35, 102278. [CrossRef]

7. Hady, F.M.; Ibrahim, F.S.; Abdel-Gaied, S.M.; Eid, M.R. Radiation effect on viscous flow of a nanofluid and heat transfer over a nonlinearly stretching sheet. Nanoscale Res. Lett. 2012, 7, 229. [CrossRef]

8. Pinem, M.P.; Wardhono, E.Y.; Nadaud, F.; Clausse, D.; Saleh, K.; Guénin, E. Nanofluid to nanocomposite film: Chitosan and cellulose-based edible packaging. Nanomaterials 2020, 10, 660. [CrossRef]

9. Chen, H.; Chen, Z.; Yang, H.; Wang, J.; Zhao, H. Lowest liquid phase saturation point temperature-phase separation-viscosity model for the optimal formulation of mixed fluoride salt. Sol. Energy Mater. Sol. Cells 2021, 227, 111107. [CrossRef]

10. Rakkappan, S.R.; Sivan, S.; Ahmed, S.N.; Naarendharan, M.; Sudhir, P.S. Preparation, characterisation and energy storage performance study on 1-Decanol-expanded graphite composite PCM for air-conditioning cold storage system. Int. J. Refrig. 2021, 123, 91-101. [CrossRef]

11. Li, Y.-X.; Alqsair, U.F.; Ramesh, K.; Khan, S.U.; Khan, M.I. Nonlinear heat source/sink and activation energy assessment in double diffusion flow of micropolar (non-Newtonian) nanofluid with convective conditions. Arab. J. Sci. Eng. 2021, in press. [CrossRef]

12. Ali, W.; Mahmood, S.; Chammam, W.; Ul-Haq, W.; Khan, W.A.; Abbas, S.Z. Mathematical modeling and chemical conduct considering non-Newtonian nanofluid by utilizing heat flux features. Soft Comput. 2020, 24, 11829-11839. [CrossRef]

13. Abbas, S.Z.; Farooq, S.; Chu, Y.M.; Chammam, W.; Khan, W.A.; Riahi, A.; Rebei, H.A.; Zaway, M. Numerical study of nanofluid transport subjected to the collective approach of generalized slip condition and radiative phenomenon. Arab. J. Sci. Eng. 2021, 46, 6049-6059. [CrossRef] 
14. Irfan, M.; Khan, M.; Khan, W.; Alghamdi, M.; Ullah, M.Z. Influence of thermal-solutal stratifications and thermal aspects of non-linear radiation in stagnation point Oldroyd-B nanofluid flow. Int. Commun. Heat Mass Transf. 2020, 116, 104636. [CrossRef]

15. Anwar, T.; Kumam, P.; Baleanu, D.; Khan, I.; Thounthong, P. Radiative heat transfer enhancement in MHD porous channel flow of an Oldroyd-B fluid under generalized boundary conditions. Phys. Scr. 2020, 95, 115211. [CrossRef]

16. Ramzan, M.; Howari, F.; Chung, J.D.; Kadry, S.; Chu, Y.-M. Irreversibility minimization analysis of ferromagnetic Oldroyd-B nanofluid flow under the influence of a magnetic dipole. Sci. Rep. 2021, 11, 4810. [CrossRef]

17. Abbas, S.; Khan, W.; Waqas, M.; Irfan, M.; Asghar, Z. Exploring the features for flow of Oldroyd-B liquid film subjected to rotating disk with homogeneous/heterogeneous processes. Comput. Methods Programs Biomed. 2020, 189, 105323. [CrossRef]

18. Waqas, H.; Imran, M.; Muhammad, T.; Sait, S.M.; Ellahi, R. Numerical investigation on bioconvection flow of Oldroyd-B nanofluid with nonlinear thermal radiation and motile microorganisms over rotating disk. J. Therm. Anal. Calorim. 2020, 145, 523-539. [CrossRef]

19. Tulu, A.; Ibrahim, W. Effects of second-order slip flow and variable viscosity on natural convection flow of $\mathrm{CNTs}^{-} \mathrm{Fe}_{3} \mathrm{O}_{4} / \mathrm{Water}$ hybrid nanofluids due to stretching surface. Math. Probl. Eng. 2021, 2021, 84097194. [CrossRef]

20. Eid, M.R.; Nafe, M.A. Thermal conductivity variation and heat generation effects on magneto-hybrid nanofluid flow in a porous medium with slip condition. Waves Random Complex Media 2020, 1-25. [CrossRef]

21. Li, Q.; Li, C.; Du, Z.; Jiang, F.; Ding, Y. A review of performance investigation and enhancement of shell and tube thermal energy storage device containing molten salt based phase change materials for medium and high temperature applications. Appl. Energy 2019, 255, 113806. [CrossRef]

22. Hussien, A.A.; Abdullah, M.Z.; Yusop, N.M.; Al-Kouz, W.; Mahmoudi, E.; Mehrali, M. Heat transfer and entropy generation abilities of MWCNTs/GNPs hybrid nanofluids in microtubes. Entropy 2019, 21, 480. [CrossRef] [PubMed]

23. Ahmad, S.; Nadeem, S.; Ullah, N. Entropy generation and temperature-dependent viscosity in the study of SWCNT-MWCNT hybrid nanofluid. Appl. Nanosci. 2020, 10, 5107-5119. [CrossRef]

24. Kumar, V.; Sarkar, J. Particle ratio optimization of $\mathrm{Al}_{2} \mathrm{O}_{3}-\mathrm{MWCNT}$ hybrid nanofluid in minichannel heat sink for best hydrothermal performance. Appl. Therm. Eng. 2020, 165, 114546. [CrossRef]

25. Kumar, V.; Sarkar, J. Experimental hydrothermal behavior of hybrid nanofluid for various particle ratios and comparison with other fluids in minichannel heat sink. Int. Commun. Heat Mass Transf. 2019, 110, 104397. [CrossRef]

26. Ma, H.; Duan, Z.; Su, L.; Ning, X.; Bai, J.; Lv, X. Fluid flow and entropy generation analysis of $\mathrm{Al}_{2} \mathrm{O}_{3}-\mathrm{water}$ nanofluid in microchannel plate fin heat sinks. Entropy 2019, 21, 739. [CrossRef] [PubMed]

27. Abu-Libdeh, N.; Redouane, F.; Aissa, A.; Mebarek-Oudina, F.; Almuhtady, A.; Jamshed, W.; Al-Kouz, W. Hydrothermal and entropy investigation of $\mathrm{Ag} / \mathrm{MgO} / \mathrm{H}_{2} \mathrm{O}$ hybrid nanofluid natural convection in a novel shape of porous cavity. Appl. Sci. 2021, 11, 1722. [CrossRef]

28. Almuhtady, A.; Alhazmi, M.; Al-Kouz, W.; Raizah, Z.; Ahmed, S. Entropy generation and MHD convection within an inclined trapezoidal heated by triangular fin and filled by a variable porous media. Appl. Sci. 2021, 11, 1951. [CrossRef]

29. Tiwari, R.K.; Das, M.K. Heat transfer augmentation in a two-sided lid-driven differentially heated square cavity utilizing nanofluids. Int. J. Heat Mass Transf. 2007, 50, 2002-2018. [CrossRef]

30. Mabood, F.; Bognár, G.; Shafiq, A. Impact of heat generation/absorption of magnetohydrodynamics Oldroyd-B fluid impinging on an inclined stretching sheet with radiation. Sci. Rep. 2020, 10, 17688. [CrossRef]

31. Aziz, A.; Jamshed, W.; Aziz, T.; Bahaidarah, H.M.S.; Rehman, K.U. Entropy analysis of Powell-Eyring hybrid nanofluid including effect of linear thermal radiation and viscous dissipation. J. Therm. Anal. Calorim. 2020, 143, 1331-1343. [CrossRef]

32. Jamshed, W.; Nisar, K.S.; Gowda, R.J.P.; Kumar, R.N.; Prasannakumara, B.C. Radiative heat transfer of second grade nanofluid flow past a porous flat surface: A single-phase mathematical model. Phys. Scr. 2021, 96, 064006. [CrossRef]

33. Jamshed, W.; Aziz, A. A comparative entropy based analysis of $\mathrm{Cu}$ and $\mathrm{Fe}_{3} \mathrm{O}_{4}$ /methanol Powell-Eyring nanofluid in solar thermal collectors subjected to thermal radiation, variable thermal conductivity and impact of different nanoparticles shape. Results Phys. 2018, 9, 195-205. [CrossRef]

34. Arunachalam, M.; Rajappa, N.R. Forced convection in liquid metals with variable thermal conductivity and capacity. Acta Mech 1978, 31, 25-31. [CrossRef]

35. Mukhtar, T.; Jamshed, W.; Aziz, A.; Kouz, W.A. Computational investigation of heat transfer in a flow subjected to MHD of Maxwell nanofluid over a stretched flat sheet with thermal radiation. Numer. Methods Partial. Differ. Equ. 2020, in press. [CrossRef]

36. Iqbal, Z.; Azhar, E.; Maraj, E.N. Performance of nano-powders $\mathrm{SiO}_{2}$ and $\mathrm{SiC}$ in the flow of engine oil over a rotating disk influenced by thermal jump conditions. Phys. A 2021, 565, 125570. [CrossRef]

37. Brewster, M.Q. Thermal Radiative Transfer and Features; John Wiley and Sons: New York, NY, USA, 1992.

38. Jamshed, W. Numerical investigation of MHD impact on Maxwell nanofluid. Int. Commun. Heat Mass Transf. 2021, 120, 104973. [CrossRef]

39. Jamshed, W.; Nisar, K.S. Computational single phase comparative study of williamson nanofluid in parabolic trough solar collector via Keller box method. Int. J. Energy Res. 2021, 45, 10696-10718. [CrossRef]

40. Jamshed, W.; Eid, M.R.; Nasir, N.A.A.M.; Nisar, K.S.; Aziz, A.; Shahzad, F.; Saleel, C.A.; Shukla, A. Thermal examination of renewable solar energy in parabolic trough solar collector utilizing Maxwell nanofluid: A noble case study. Case Stud. Therm. Eng. 2021, 27, 101258. [CrossRef] 
41. Jamshed, W.; Mishra, S.; Pattnaik, P.; Nisar, K.S.; Devi, S.S.U.; Prakash, M.; Shahzad, F.; Hussain, M.; Vijayakumar, V. Features of entropy optimization on viscous second grade nanofluid streamed with thermal radiation: A Tiwari and Das model. Case Stud. Therm. Eng. 2021, 27, 101291. [CrossRef]

42. Jamshed, W.; Akgül, E.K.; Nisar, K.S. Keller box study for inclined magnetically driven Casson nanofluid over a stretching sheet: Single phase model. Phys. Scr. 2021, 96, 065201. [CrossRef]

43. Jamshed, W.; Devi, S.U.; Nisar, K.S. Single phase based study of Ag-Cu/EO Williamson hybrid nanofluid flow over a stretching surface with shape factor. Phys. Scr. 2021, 96, 065202. [CrossRef]

44. Jamshed, W.; Nisar, K.S.; Ibrahim, R.W.; Shahzad, F.; Eid, M.R. Thermal expansion optimization in solar aircraft using tangent hyperbolic hybrid nanofluid: A solar thermal application. J. Mater. Res. Technol. 2021, 14, 985-1006. [CrossRef]

45. Jamshed, W.; Eid, M.R.; Nisar, K.S.; Nasir, N.A.A.M.; Edacherian, A.; Saleel, C.A.; Vijayakumar, V. A numerical frame work of magnetically driven Powell-Eyring nanofluid using single phase model. Sci. Rep. 2021, 11, 16500. [CrossRef]

46. Jamshed, W. Thermal augmentation in solar aircraft using tangent hyperbolic hybrid nanofluid: A solar energy application. Energy Environ. 2021, 1-44. [CrossRef]

47. Keller, H.B. A new difference scheme for parabolic problems. In Numerical Solutions of Partial Differential Equations; Hubbard, B., Ed.; Academic Press: New York, NY, USA, 1971; Volume 2, pp. 327-350.

48. Ishak, A.; Nazar, R.; Pop, I. Mixed convection on the stagnation point flow towards a vertical, continuously stretching sheet. ASME J. Heat Transf. 2007, 129, 1087-1090. [CrossRef]

49. Ishak, A.; Nazar, R.; Pop, I. Boundary layer flow and heat transfer over an unsteady stretching vertical surface. Meccanica 2009, 44, 369-375. [CrossRef]

50. Abolbashari, M.H.; Freidoonimehr, N.; Nazari, F.; Rashidi, M.M. Entropy analysis for an unsteady MHD flow past a stretching permeable surface in nano-fluid. Powder Technol. 2014, 267, 256-267. [CrossRef]

51. Das, S.; Chakraborty, S.P.; Jana, R.N.; Makinde, O.D. Entropy analysis of unsteady magneto-nanofluid flow past accelerating stretching sheet with convective boundary condition. Appl. Math. Mech. 2015, 36, 1593-1610. [CrossRef] 